\title{
Aplicación de un Sistema de Información Geográfica a la pros- pección del Yacimiento del Cancho Gordo (La Cabrera, Madrid)
}

\author{
Mercedes Planas Garrido \\ Universidad Autónoma de Madrid
}

\section{Resumen}

El artículo que a continuación se presenta constituye una muestra más de la aportación de nuevas aplicaciones informáticas en el campo de la arqueología. La utilización de un Sistema de Información Geográfica en el estudio del yacimiento de la Edad del Bronce del Cancho Gordo (Madrid) y más concretamente, en su aplicación como herramienta complementaria a la prospección arqueológica de dicho asentamiento, ha supuesto un apoyo de gran utilidad para la confirmación de las conclusiones finales del trabajo.

\section{Abstract}

The following article is yet another example of a computer application contribution to archaeological investigation. The use of a Geographical Information System in the study of a Bronze Age settlement at Cancho Gordo (Madrid), and its application as a complementary tool to the field survey, has proved to be a useful support to confirm its conclusions.

\section{INTRODUCCIÓN A LOS SISTEMAS DE INFORMACIÓN GEOGRÁFICA}

Un Sistema de Información Geográfica es una herramienta que permite ejecutar complejos análisis de datos previamente introducidos en el sistema "de forma que puede generarse nueva información mediante la identificación de las relaciones espaciales existentes entre distintos elementos geográficos" (Blasco y Baena, 1993, 180). Los datos que se introducen en el Sistema de Información Geográfica pueden ser de tipo gráfico (imágenes) o alfanuméricos (bases de datos) y su incorporación al sistema permitirá la interrelación de ambas bases de datos.

Los SIG tuvieron un desarrollo inicial más intenso en ámbitos anglosajones, pero se desarrollaron principalmente en Estados Unidos, en donde se utilizaban para tareas de cálculos de redes eléctricas, forestales o agrícolas o bien para censos, catastros, etc (Arroyo- Bishop, 1991, 169). La aplicación de los SIG en arqueología se ini- ciaría hace pocos años en Norteamérica, cuando ésta comenzara a destacar por los numerosos proyectos en los que se aplicaba la herramienta, enfocados principalmente a la valoración del potencial arqueológico (Allen y otros, 1990). Europa, al igual que en otras regiones (Sudamérica, Australia...), inicia su reto en la aplicación de los SIG a la arqueología en años posteriores, dirigido en un primer momento a la gestión del patrimonio cultural (Harris y Lock, 1995). De este modo, España se unirá a esta oleada de aplicaciones informáticas basadas fundamentalmente en "la realización y tratamiento de las cartas arqueológicas y su posterior utilización en la conservación del patrimonio" (Blasco y Baena, 1993, 179) ${ }^{1}$. Proyectos en torno a aplicaciones informáticas para el registro arqueológico y gestión de patrimonio (Cultural Resource Management, Gestión del Patrimonio Arqueológico) se han desarrollado en universidades de muchas comunidades de la Península como en Andalucía (Sevilla, Córdoba), Cataluña (Lérida)

1. Ver capítulo III en Baena, J., Blasco, C. y Quesada, F. (eds) (1999): Los S.I.G. y el análisis espacial en Arqueología, Universidad Autónoma de Madrid (81-92) 


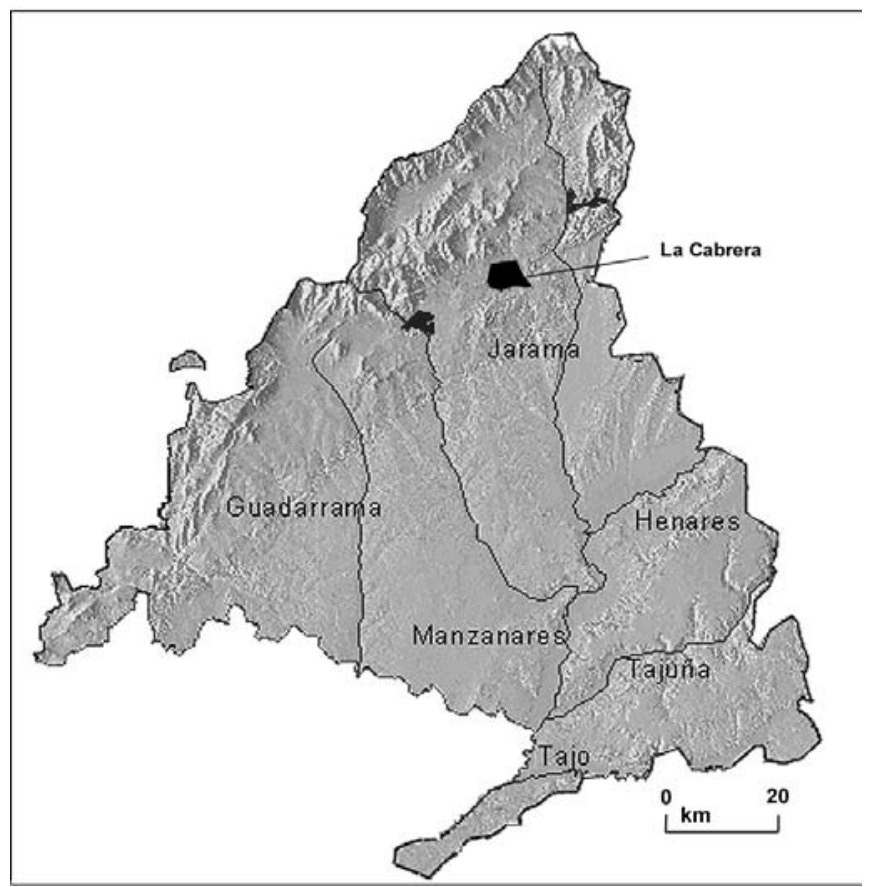

Figura 1. Localización de la Sierra de La Cabrera en la provincia de Madrid

o Galicia (Santiago de Compostela) entre otras. Igualmente, los SIG se utilizarán además como herramienta de apoyo en proyectos de análisis espacial y de estudio de patrones de asentamiento promovidos, entre otras, por las instituciones académicas (Universidad de Teruel, Jaén, Córdoba, Autónoma de Barcelona, Autónoma de Madrid). Es en esta dirección hacia donde se decidió orientar la creación del SIG aplicado al yacimiento del Cancho Gordo: estudio de la prospección y análisis espacial del yacimiento ${ }^{2}$.

Una de las primeras cuestiones que se planteó en los inicios de los SIG era demostrar en qué medida esta aplicación informática podía ayudar a la investigación arqueológica. En este sentido, la interrelación de coberturas de información permitían al arqueólogo "generar modelos de simulación” que resultaban muy útiles para la investigación arqueológica (Espiago y Baena, 1999, 38). Anteriormente al desarrollo de los SIG muchas de las preguntas relacionadas con la organización social y agrupación espacial o territorial únicamente podían tratarse a través de técnicas de difícil aplicación e interpretación, por lo que la combinación de la teoría y método que proporcionan la arqueología del paisaje y el SIG supone un avance en el estudio de sistemas sociales del pasado en relación con su medio físico y cultural (Savage, 1990, 29). La posibilidad de establecer coberturas de intervisibilidad de yacimientos, de distancias entre diferentes asenta-

2. Este artículo corresponde a un extracto de la Memoria de Licenciatura de Mercedes Planas Garrido: El yacimiento del Cancho Gordo (La Cabrera, Madrid): aplicación mientos, de accesibilidad a recursos naturales próximos, de simulaciones topográficas, etc., hacen de estos sistemas una herramienta enormemente útil en la interpretación arqueológica de yacimientos.

No obstante, se debe tener en cuenta que, como dice D. Arroyo- Bishop (1991, 170) en alguna ocasión, un sig “....no es sencillamente un programa informático para hacer mapas, sino un instrumento que permite establecer relaciones dinámicas entre datos". No debe confundirse en este sentido el Sistema de Información Geográfica con un programa de tratamiento de imagen, ya que en muchas ocasiones estos sistemas se utilizan únicamente como representación gráfica sin ninguna aplicación adicional (cálculo de visibilidades, pendientes, orientaciones, tipos de suelos.). El hecho de que la tecnología SIG se utilice en algunas ocasiones como sistemas de diseño asistido por ordenador ha suscitado diversas críticas en las que se afirma el escaso valor de las "pretty pictures” (fotos bonitas) (Kvamme, 1995).

\section{El YACIMIENTO}

El yacimiento del cerro del Cancho Gordo (La Cabrera, Madrid), situado a 50 kilómetros del núcleo urbano de la provincia de Madrid (Figura 1), corresponde a la elevación más occidental de la Sierra de La Cabrera enclavada ésta en el sector oriental del Sistema Central y ubica-

de un Sistema de Información Geográfica. Universidad Autónoma, Noviembre, 2000. Inédito. 
da en las estribaciones meridionales de la Sierra de Guadarrama, dentro de la comarca madrileña de la Cuenca del Jarama.

El conocimiento de este asentamiento prehistórico en la sierra madrileña vino motivado por la existencia de una colección de material arqueológico recogido por un amateur local a la que tuvimos acceso gracias a las facilidades ofrecidas por el ayuntamiento de La Cabrera. Ante la variedad cronológica que ofrecían dichos materiales (se identificó cerámica neolítica y de horizontes de la Edad del Bronce madrileña de Protocogotas y Cogotas I) se decidió realizar los trabajos arqueológicos pertinentes para el estudio del mencionado cerro.

El cerro del Cancho Gordo se eleva hasta una cota máxima de 1.566,88 metros $\mathrm{y}$, al igual que el resto de la sierra, se caracteriza por su topografía particular de bloques redondeados de granito, denominados bolos, en la parte inferior del mismo, y de bloques más irregulares en la parte superior que constituyen una estructura de perfil apuntado, reconocible desde puntos muy alejados de la región. Su localización geográfica corresponde a la hoja $\mathrm{n}^{\mathrm{o}} 484$ (6-6 y 6-7) del mapa parcelario 1:5.000 de la Comunidad de Madrid y las coordenadas UTM del cerro son: $\mathrm{x}^{-} 446.210$ y- 4.525.320

Esta elevación tiene como particularidad la enorme diferencia en la morfología de sus laderas que, en la vertiente sur, presenta una pendiente muy pronunciada mientras que en la septentrional tiende a suavizarse. Así, en la falda meridional existe una fuerte ruptura de pendiente con paredes verticales que enlazan con la superficie topográfica de base a través de un talud con fuerte inclinación, determinado en parte por la acumulación de derrubios graníticos. El ascenso por esta ladera a la cima del cerro se hace con dificultad a pesar de que en las zonas más bajas de ésta la pendiente sea menos pronunciada (Figura 2). Al contrario de lo que ocurre en la vertiente meridional, en la denominada Ladera del Buitre, en la cara norte de la sierra, el relieve es más suave con una pendiente topográfica menos pronunciada y menos irregular, que garantiza el acceso a las cotas más elevadas del cerro con mayor facilidad. La parte alta del cerro del Cancho Gordo, sin embargo, se caracteriza por zonas más llanas sin la presencia de grandes pendientes, formando pequeñas llanuras rodeadas por los grandes bloques de granito entre los que se han formado grietas debido probablemente a la erosión del agua y el viento y a la acción del hielo. De entre estas grietas formadas en el granito del cerro por la acción erosiva, se han considerado dos de ellas como posibles abrigos utilizados durante la Prehistoria reciente. Estos abrigos están orientados hacia el sur y sureste y ambos están protegidos por altas paredes de granito, que constituyen unas condiciones favorables

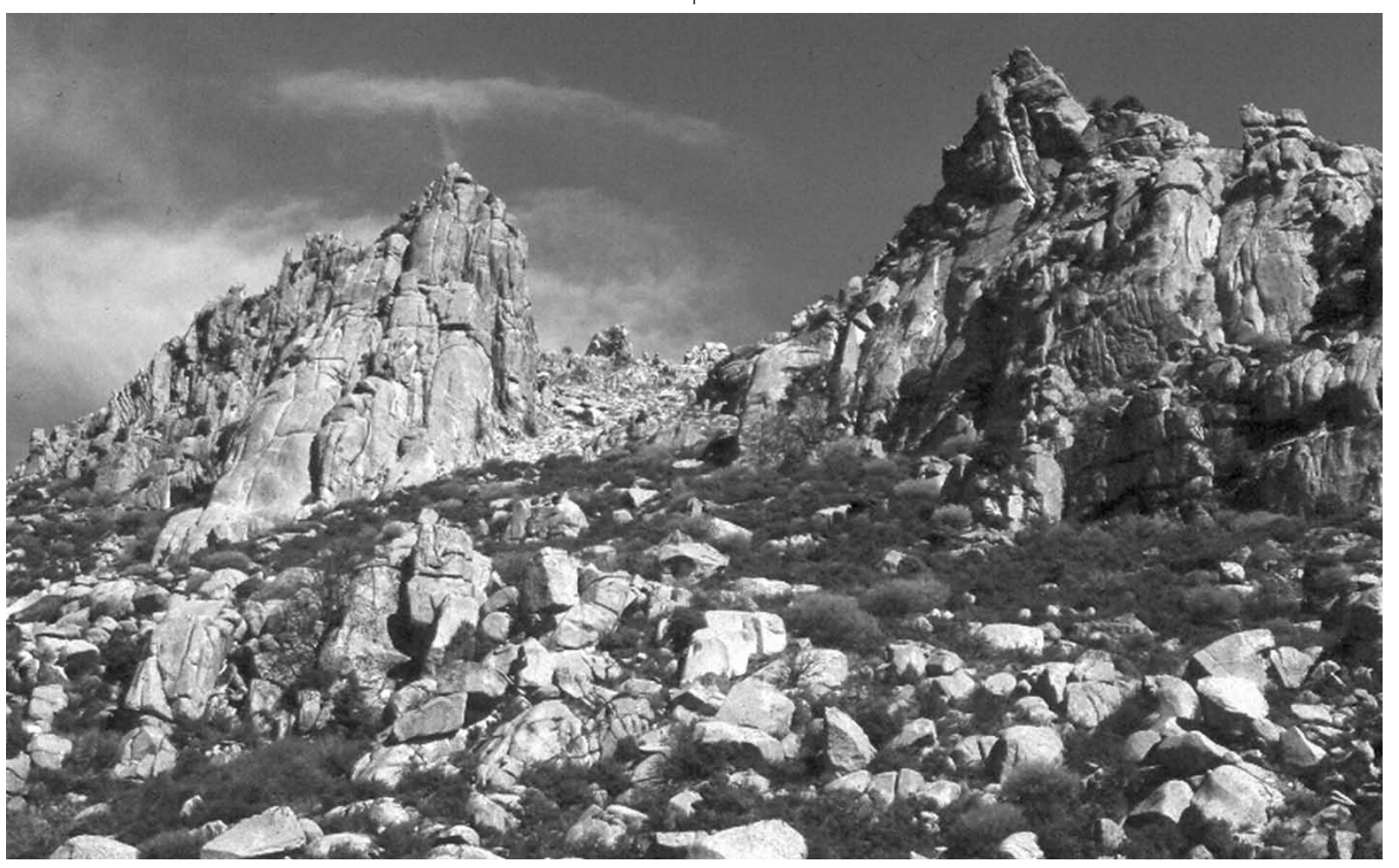

Figura 2. Vista panorámica del cerro del Cancho Gordo (Sierra de La Cabrera, Madrid) 
para la ocupación. De este modo, una de las cuestiones de interés para la prospección arqueológica era la comprobación de la ocupación de estos abrigos durante el II y II milenio a.C.

\section{Metodología de trabajo}

\subsection{La prospección}

El trabajo de campo que se realizó en el yacimiento del Cancho Gordo fue la prospección de superficie del cerro. Para poder elaborar un estudio exhaustivo de la zona, era necesario realizar una prospección intensiva ${ }^{3}$ de cobertura total cuyos resultados constituirían una fuente de información enormemente válida para posteriormente elaborar mapas de distribución de los materiales arqueológicos. En efecto, la elección de la prospección de cobertura total presentaba ciertas ventajas con respecto a un muestreo aleatorio, ya que la posibilidad de documentar la localización exacta de los materiales recogidos facilitaba en gran medida nuestros planteamientos posteriores. En este sentido, este tipo de prospección ofrece resultados fiables de concentraciones de material o de vacíos del mismo, a pesar de advertir que algunas de estas acumulaciones localizadas en determinadas áreas del cerro podrían no responder a la localización exacta de un yacimiento. Por ello, los más que probables procesos postdeposicionales deberán ser tenidos en cuenta a la hora de la valoración final de los resultados de la prospección. No obstante, se insiste una vez más en que con la realización de una prospección de cobertura total se puede obtener una visión más completa del modelo de asentamiento de las comunidades que poblaron la Sierra Norte de Madrid durante la Prehistoria reciente.

El trabajo de campo en el Cerro del Cancho Gordo se inició con el reconocimiento topográfico de la zona para precisar la metodología de prospección que se iba a aplicar posteriormente. De esta manera, se observó que el cerro presentaba unas características topográficas muy particulares, con importantes pendientes y desniveles así como una frondosa vegetación, que reducía

3. A pesar de que algunos autores consideran el término de «intensiva» algo «utópico» por la dificultad que conlleva "el examen completo y real de toda la superficie del terreno" (Ruiz Zapatero y Fernández Martínez, 1993, 91), continuaremos haciendo referencia a la propección de cobertura total como intensiva.

4. En este sentido, supimos por uno de los monjes del convento de San Antonio al pie de la ladera del Cerro del Cancho Gordo que la ladera sur y parte alta del en gran medida las posibilidades de localización de hallazgos. Por ello, se decidió aplicar una prospección intensiva únicamente en la ladera sur y en la parte superior del cerro del Cancho Gordo que además de ser las zonas de mayor facilidad para el estudio (zonas de fácil acceso para los prospectores) ofrecían a simple vista un mayor número de material ${ }^{4}$. En la vertiente septentrional, por el contrario, y ante la aparente escasez de material arqueológico, se realizó una prospección de muestreo menos exhaustivo que la diseñada para la ladera meridional.

Para la realización de la prospección intensiva de cobertura total de la ladera sur se decidió establecer una trama de cuadriculas de 100x100 metros, haciéndola coincidir con el norte del mapa topográfico. El trazado de la malla que establecimos en un primer momento en el mapa parcelario 1:5.000 de la Comunidad de Madrid (hoja 6-6 y 6-7) se extendía a lo largo de 40 ha.. Posteriormente, al intentar delimitar las cuadrículas en el terreno, se consideró que el trazado teórico del estudio era demasiado ambicioso, ya que muchas de las cuadrículas resultaban improspectables (debido a la antes mencionada densidad de vegetación y agudas pendientes) y por consiguiente carentes de información arqueológica. La malla de prospección se redujo finalmente a una extensión de 21 ha. ${ }^{5}$, dividida en 21 cuadrículas, subdivididas en cuatro sectores de 50x50 metros (cuya identificación se haría con los números 1, 2, 3 y 4). En las cuadrículas de la parte superior del cerro (coincidiendo con las zonas de mayor concentración de material arqueológico) se estimó conveniente dividirlas en 16 sectores de $25 \times 25$ metros cada uno para un estudio más profundo de la localización del material arqueológico (Figura 3). Para la nomenclatura de la trama se tomó como referencia la utilizada por Almagro Gorbea y BenitoLópez (1994) en las prospecciones de Perales de Tajuña (Madrid) cuya utilización facilitaría en gran medida la identificación de las cuadrículas a los prospectores. Por tanto, la identificación de las cuadrículas se realizó del siguiente modo: localizando el punto 0,0 en el ángulo SO de la trama, se designó al eje de ordenadas con letras mayúsculas

cerro era de donde procedía la mayor parte del material de la colección particular que nos había sido mostrada.

5. Las coordenada UTM de los cuatro vértices de la trama son las siguientes:

$$
\begin{aligned}
& \text { - ángulo NO: } 4.525 .380 \text { / } 446.125 \\
& \text { - ángulo NE: } 4.525 .380 \text { / } 446.435 \\
& \text { - ángulo NE: } 4.525 .380 \text { / } 446.435 \\
& \text { - ángulo SO: } 4.525 .575 \text { / } 446.125
\end{aligned}
$$




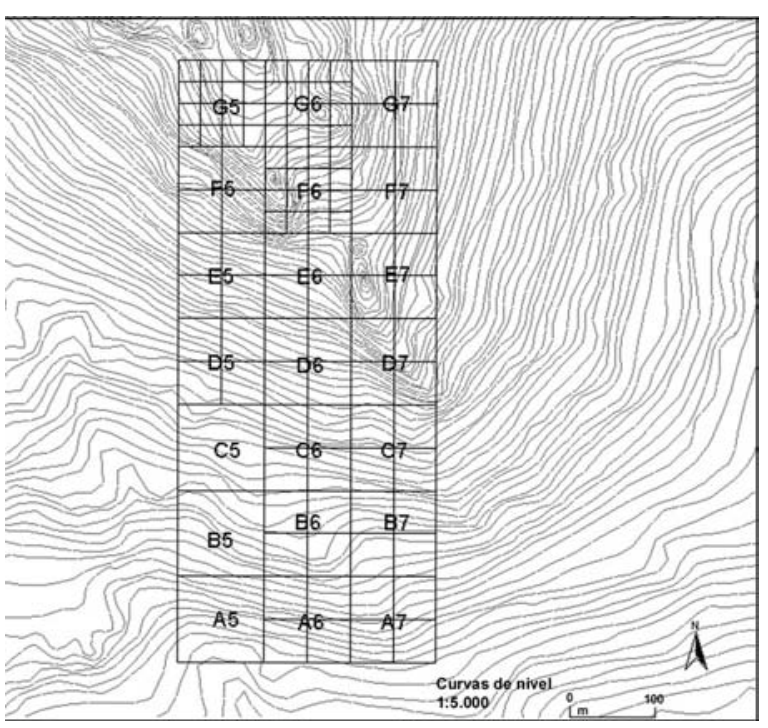

Figura 3. Cuadrícula de prospección del Cancho Gordo (La Cabrera, Madrid)

y al eje de abcisas con números. De esta manera, cada cuadrícula quedaría identificada con una letra y un número. Los sectores de cada cuadrante se enumerarían del 1 al 4 y los subsectores con letras de la a $a$ la $d$.

Una vez decidido el trazado final de la trama de prospección en el mapa procedimos a la delimitación de la misma en el campo. Para ello, se contó con la ayuda de un GPS (Glogal Positional System) que, a pesar de que ser conocido su margen de error, no suponía una distorsión importante en los resultados de nuestro estudio. Este margen de error puede deberse a distintas causas, entre las que cabría mencionar los posibles ruidos en el receptor (fallos en la calidad de la señal), las variaciones en la velocidad de transmisión de la señal de radio, o en el reloj del aparato (Amado, 1997). La utilización del GPS en el estudio se vio motivada principalmente por ser un herramienta de fácil manejo y accesibilidad. Previamente, se intentaron otros métodos para establecer las cuadrículas (por puntos de demora) pero resultó menos preciso y más complicado de realizar debido sobre todo a la orografía tan característica del lugar. Por tanto, se procedió a la

6. Preferimos realizar la prospección con prospectores cualificados ya que según J. E. Benito-López y L. C. San Miguel (1993, 146) el factor experiencia en los componentes (prospectores) es apreciable, ya que aquellos que carecen de experiencia "son los autores de los hallazgos más evidentes que detectaron un menor número de yacimientos.".

7. En este prospección que dirigimos la abajo firmante junto a $\mathrm{M}^{\mathrm{a}} \mathrm{C}$. Blasco no pudimos aplicar una distancia demarcación de los puntos de intersección entre las cuadrículas con la ayuda del GPS y posteriormente de los sectores de la parte superior del cerro para facilitar la tarea de prospección. La identificación de los límites de cada cuadrante se realizó con materiales de fácil percepción por los prospectores de cada cuadrícula.

La prospección intensiva del cerro del Cancho Gordo, que se realizó a lo largo de todo el mes de octubre de 1998 en días alternos de la semana, contó con la ayuda de alumnos y licenciados de la Universidad Autónoma de Madrid, bajo la dirección de la Doctora $\mathrm{M}^{\mathrm{a}}$ Concepción Blasco Bosqued y de la que escribe, y a los que agradecemos enormemente su colaboración ${ }^{6}$. Durante la prospección se colocó a los prospectores cada 20 metros a lo largo del eje de abcisas ${ }^{7}$, por lo que cada uno de los voluntarios tendría un campo de visión de diez metros a ambos lados. De este modo, se colocaron cinco prospectores a lo largo de 100 metros y se comenzó la ascensión por la ladera en dirección hacia el norte geográfico. Por cada cuadrícula de 100×100 metros cuadrados recorrida por los prospectores se invertía una media de treinta minutos, que según los criterios de algunos autores (Ruiz Zapatero y Fernández Martínez, 1993) se puede considerar una prospección de intensidad casi alta ${ }^{8}$.

El criterio de selección que se siguió en la prospección fue la recogida total de todo el material de superficie, ya fuesen muestras cerámicas como restos de industria lítica o de otra materia prima. El material, durante su recogida se fue separando por sectores y subsectores en bolsas con identificación de cada cuadrícula.

En la ladera norte del cerro, por el contrario, se optó por realizar una prospección de muestreo aleatorio, sin establecer una trama de tanta precisión como en la ladera sur. La elección de este tipo de prospección para esta vertiente se decidió al demostrarse un menor interés desde el punto de vista arqueológico (escasez de material) en comparación con la parte meridional del cerro que aparentemente mostraba una mayor concentración de material. De este modo ambas laderas del cerro, la meridional y septentrional

menor entre los prospectores debido a que la densa vegetación nos lo impedía.

8. Según los propios autores los "intervalos de 10 ó 15 metros pueden calificarse de alta o muy alta" (Ruiz Zapatero y Fernández Martínez, 1993, 90). En otros casos la intensidad de la prospección es tan alta que la distancia entre los prospectores se redujo a 1 metro, y el tiempo invertido por cada 20 metros cuadrados era de cinco minutos (Foard, 1978). 
quedarían incluidas en el estudio, aunque por las razones mencionadas anteriormente, con diferencias en la intensidad de su intervención.

\subsection{Aplicación de un SIG en el cerro del Cancho Gordo}

La creación de un SIG requiere un planteamiento previo de los objetivos que se pretende con su aplicación. Es importante tener en cuenta en qué medida un SIG puede beneficiar los resultados de un estudio y si constituye una herramienta de apoyo de la que no es posible disponer con otros medios (Zubrow, 1990). Por ello se decidió valorar a priori cuales eran las ventajas y desventajas de su aplicación en este estudio. Por un lado, la aplicación de un SIG proporciona una información de suma utilidad a la hora de la interpretación de los resultados de la prospección: esto es, una combinación de factores, como visibilidad del territorio, pendientes del área de estudio, proximidad a cursos de agua y materias primas o relación espacial con otros asentamientos, que integrados en un sistema geográfico puedan complementar la información de una prospección. Por otro lado, el SIG permite localizar geográficamente los hallazgos para así realizar un estudio de la concentración del material que, sin la aplicación del sistema, hubiera "ralentizado" el desarrollo de la investigación. Asimismo, la elaboración de un modelo digital del terreno del cerro del Cancho Gordo podría facilitar la simulación de ciertos procesos que de otra manera sería imposible realizar, como el recorrido óptimo de desplazamiento en la caída de material.

La elección del equipo informático no supuso gran dificultad. El hecho de que el sistema lo fuésemos a utilizar personalmente y que por consiguiente no era necesaria la ayuda de más ordenadores, utilizamos la plataforma de Xwindows para PCs, con procesador de amplia memoria (64 Mb RAM y 8 Gb ROM). Como periféricos de entrada utilizamos la tableta digitalizadora y el escáner (HP Scanjet IICX) y como periféricos de salida la impresora (HP 690 C). El software utilizado ha sido ArcView, versión 3.1 (ESRI, 1996), una marca registrada de Ennvironmental Systems Research Institute, Inc.. A pesar de las posibilidades de este software en la integración de datos, se decidió utilizar una extensión adicional al paquete inicial (Spatial Analyst) que constituye una herramienta de apoyo fundamental en el análisis y modelado espacial de nuestro trabajo. A través de la herramienta de Análisis Espacial se podría analizar mejor la relación espacial de los datos, establecer cuestionarios con los datos (query builder) y mejorar la visualización de los mismos.
Una de las finalidades para la que fue creado el Sistema de Información Geográfica era la de realizar un estudio de la distribución de las evidencias arqueológicas con el fin de establecer las causas que delimitan la acumulación de estos materiales. Una acumulación de material que podría estar causada por diferentes motivos tales como procesos postdeposicionales (agentes erosivos) o procesos antrópicos. Era por tanto necesario detallar con precisión la localización del material en el cerro del Cancho Gordo. La simbolización de los resultados de la prospección en la que se representaban las acumulaciones de material arqueológico sería incluida, junto con otras coberturas de información vinculadas a ésta, en el SIG para intentar aclarar el origen de esas concentraciones. Para relacionar los datos de las coberturas era necesario contar con la representación del cerro de estudio. Para ello se creó el Modelo Digital del Terreno (MDT) de la zona que se ha venido definiendo como la "representación digital del terreno en forma adecuada para su procesamiento informático" (Stefanovic, 1984).

Los Modelos Digitales del Terreno tienen una notable aplicación en el campo de la arqueología. A partir de la elaboración de estos modelos con la utilización de un SIG se crean modelos arqueológicos predictivos (predictive modelling) para realizar estimaciones de localización, por ejemplo, de asentamientos prehistóricos (Warren y Asch, 2000, 25). Según algunos investigadores, los MDT se apoyan en dos premisas básicas: la primera se fundamenta en la idea de que las sociedades antiguas elegían el lugar de ocupación condicionados por las características del entorno natural y, la segunda, en que los factores del entorno que influencian esta elección están representados, por lo menos indirectamente, en los mapas modernos de variación medioambiental (Warren y Asch, 2000,6). Estos modelos hacen posible la predicción de que aparezca un asentamiento en zonas en las que las variables ambientales son favorables y por el contrario, de localizar zonas con mayor probabilidad de ausencia de asentamiento (nonsite). De este modo, la elaboración de un Modelo Digital del Terreno supone una herramienta de enorme magnitud en los análisis de modelos predictivos.

Los métodos para la obtención de datos en la creación del MDT dependen del tamaño de la zona que se quiera levantar, la precisión requerida y el tipo de información que se quiera obtener del modelo. Existen tres métodos principales utilizados para la captura de la información altimétrica: el método topográfico, costoso por la gran precisión en la cota de los puntos, los métodos fotogramétricos y de teledetección, que recrea un modelo tri- 


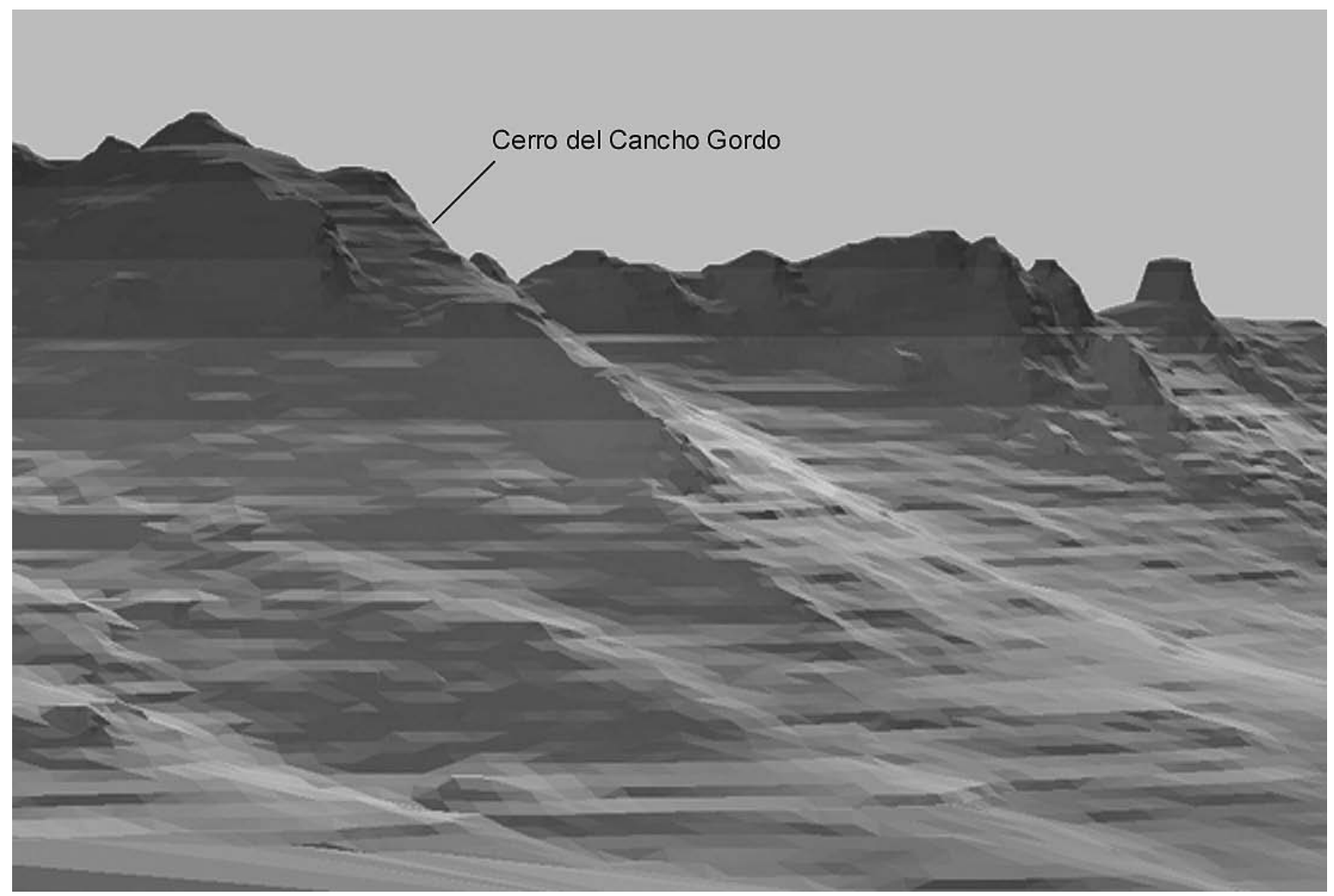

Figura 4. Modelo Digital del Terreno del Cancho Gordo (La Cabrera, Madrid)

dimensional del terreno a partir de fotografías aéreas y la digitalización de documentos cartográficos, en el que se digitalizan las curvas de nivel de los mapas. En el caso del Cancho Gordo se utilizó el último método mencionado, en el que se utilizó la cartografía de mapas parcelarios a escala 1:5.000 para mayor precisión del modelo (Figura 4).

Para el análisis del Cancho Gordo, se fueron superponiendo las capas de información a las que se hacía referencia anteriormente. Estas coberturas de información contaban con una base de datos asociada a cada una de ella. En la base de datos del sistema se incorporaron todos aquellos datos que posteriormente serían utilizados para establecer rangos de intensidad en la información. A continuación se detallan las coberturas de información que se han incorporado al Sistema de Información Geográfica del cerro del Cancho Gordo:

- En primer lugar se creó una cobertura que correspondía a la trama de cuadrículas de la prospección que denominamos TRAMA. Dicha trama se representó en formas de polígonos en el Sistema de Información sobre una extensión de 70 ha. dividida en cuadrículas de 100x100m cada una; no obstante, la prospección final se realizó sobre una extensión de 21 ha. (21 cuadrículas de $100 \times 100 \mathrm{~m}$.). A esta capa se le asoció una tabla cuyos campos de infor- mación se fueron completando a medida que se obtenían los datos de la prospección. Así, esta tabla asociada a la capa "trama"contenía el nombre de la cuadrícula y las subdivisiones de cada una (ya sea de 50x50m. y/o de 25x25m.) además de varios campos (de carácter numérico) con sus datos asociados:

- ID. En este campo se introdujeron 4 dígitos. Los dos primeros correspondían al identificador del polígono, el tercero a la división de la cuadrícula en 50x50m., y el cuarto dígito a la subdivisión de $25 \times 25 \mathrm{~m}$. Si no hubiera división de 50x50m. o de $25 \times 25 \mathrm{~m}$. se utilizaría el 0 .

Como ejemplo: 2524 -cuadrícula 25, sector 2, subsector 4 .

- Cuadrícula. Este campo corresponde a las siglas de las cuadrículas que se han utilizado en el trabajo de campo. Se designó el eje de abcisas con letras mayúsculas (AG) y el eje de ordenadas con números (110). El punto "0" de origen de la trama se estableció en el ángulo SO de la misma. Los sectores de 50x50m. se han designaron con letras de la "a" a la "d" en cada cuadrícula. Los subsectores de $25 \times 25 \mathrm{~m}$. se designaron con números del 1 al 4 en cada cuadrícula. Este campo "cuadrícula" fue subdividido a su vez en los siguientes campos: 
- Torno. Número de cerámicas a torno contabilizadas por cuadrícula.

- Mano. Número de cerámicas a mano contabilizadas por cuadrícula.

- Lítica. Numero de industria lítica que se recogió en la prospección. Si no se ha recogido material lítico (0).

- Prospección. En este campo se introdujo un solo dígito, dependiendo de si la cuadrícula se prospectó (1) o si no se realizó ningún trabajo de prospección (0).

- Intensidad del rodamiento por cuadrículas. Este dato numérico se obtuvo estableciendo el valor medio del grado de rodamiento del $50 \%$ de las piezas cerámicas recogidas por cuadrícula.

- Cobertura de la red hidrográfica de la Comunidad de Madrid representada por líneas a escala 1:25.000.

- Cobertura de red hidrográfica de la Sierra de La Cabrera a escala 1:5.000.

- Cobertura de yacimientos neolíticos, calcolíticos y de la Edad del Bronce localizados en la Comunidad de Madrid.

- Cobertura de las rutas óptimas de desplazamiento de un objeto (steepest way).

- Cobertura de curvas de nivel del cerro del Cancho Gordo a partir de los mapas parcelarios de la Comunidad de Madrid a escala 1:5.000 (hojas 6-6, 6-7). Para la creación de esta cobertura se digitalizaron manualmente las curvas de nivel ya que no se pudo acceder a la base digital de la curvas de nivel de la Comunidad de Madrid.

Simultáneamente a la creación de estas coberturas de información con bases de datos vectoriales, se añadieron otras bases de datos de tipo imagen que aportan una visión más completa para la interpretación de los datos. Debido a que el programa ArcView admite una variedad de formatos de imágenes (JPEG, BMP, TIFF...) se decidió utilizar formato TIFF. Algunas de las imágenes que se incorporaron al sistema se tomaron de la "Carta Digital de España" diseñada por el Servicio Geográfico del Ejército en el año 1994 que permite una gestión de la Cartografía en soporte digital. Estas imágenes digitales introducidas en el SIG fueron georreferenciadas ${ }^{9}$ de acuerdo con el sistema Mercator (UTM). Otra imagen incorporada al estudio del cerro por georreferenciación, fue la fotografía aérea del Cancho Gordo tomada en un vuelo de mayo de 1995 a escala 1/18.000.

\section{Resultados de la PROSPección: EL MATERIAL ARQUEOLÓGICO Y SU DISTRI- BUCión EN EL YACIMIENTO DEL CANCHO GORDO}

La distribución y localización del material arqueológico en el cerro constituye uno de los aspectos más interesantes del estudio. En primer lugar porque su análisis en profundidad ha permitido establecer áreas de posible ocupación o de actividad especializada. En segundo lugar, porque a partir de la variedad tipológico- cultural del material recogido durante la prospección del cerro del Cancho Gordo y su localización en el terreno se pueden establecer, por un lado, diferentes períodos de ocupación a lo largo del tiempo y, por otro, cambios en el patrón de asentamiento de cada momento cultural. Y en tercer lugar, porque el enorme número de material arqueológico y su variada tipología parece indicar que se trata de un yacimiento de enorme significación, tanto por estar localizado en una región (Sierra norte de Madrid) con escasos estudios arqueológicos actuales, como por situarse en el paso de conexión entre las dos mesetas actuando probablemente de vínculo entre ambas regiones.

Para abordar el estudio de la distribución de los materiales arqueológicos aparecidos en el cerro del Cancho Gordo, se consideró más apropiado hacerlo distinguiendo entre el material cerámico y el lítico tallado. De este modo, se abordará primeramente la distribución del material cerámico y posteriormente la industria lítica.

\subsection{Material cerámico}

Durante los trabajos arqueológicos de prospección realizados en el cerro del Cancho Gordo, se recogió un gran número de fragmentos cerámicos. Para acometer el estudio de los mismos con mayor detenimiento se analizó el material por factura (a mano o a torno) y grado de rodamiento (de poco rodados a muy rodados) del material. Cada una de estas variables obtenidas por cada fragmento establecería diferentes modelos o patrones de distribución que deberán ser interpretados. Para poder realizar estos modelos de distribución del material arqueológico se utilizó la herramienta informática (Sistema de

9. Se entiende por georreferenciación el proceso que permite asignar valores cartográficos a bases de datos de tipo ráster o vectorial. 
Información Geográfica) cuya aplicación ha podido completar gran parte del estudio del cerro: el análisis espacial del Cancho Gordo. A partir del Sistema de Información Geográfica se crearon capas o coberturas de información correspondientes a estas variables mencionadas, que según la representación de intensidad por cuadrícula reflejaron diferentes modelos de distribución.

\subsubsection{Distribución por factura}

Se realizó el estudio de distribución del material cerámico en el cerro separando la cerámica a mano y a trono. Con respecto a la cerámica a mano, como primera valoración del mapa de concentraciones del Cancho Gordo (Figura 5), se observó claramente el predominio de material cerámico en la parte superior del cerro en comparación con las zonas inferiores de la ladera en donde únicamente aparecía una pequeña acumulación de fragmentos.

En la concentración de cerámicas en la parte superior del cerro se apreciaron dos conjuntos bien diferenciados: uno en la parte más alta del cerro a unos 1.545 metros y el otro, a menos de 100 metros de distancia del anterior, entre 1.485 y 1.500 metros en el paso hacia la parte superior. Este paso, donde se observa el predominio de material, es una zona del cerro donde la pendiente es algo pronunciada y donde la vegeta- ción es escasa. Se insiste en estos factores de pendiente y vegetación, porque en principio se consideraron importantes en el proceso del desplazamiento de materiales ladera abajo: el incremento de la pendiente por acelerar los procesos de desplazamiento de los materiales, y la escasez de vegetación por no frenarlos. Atenerse a las consecuencias mencionadas anteriormente en relación a los efectos de pendiente y vegetación implicaría la ausencia masiva de concentraciones de material en cotas elevadas del cerro. Sin embargo, lejos de los patrones establecidos, en la parte superior del cerro del Cancho Gordo se daba una gran concentración de material que no parecía ser consecuencia directa de agentes naturales. Por tanto, y muy probablemente, la concentración de fragmentos cerámicos aparecidos en la cota de 1.500 metros correspondiera a un leve desplazamiento de los materiales arrastrados por efectos erosivos. Pero por otro lado, es posible pensar que los fragmentos de esta concentración no se hayan desplazado mucho de su disposición primaria y cuya acumulación fuera propiciada por causas de otra índole entre las que se podía considerar las antrópicas en forma de ocupación.

Por tanto, se puede pensar que las dos concentraciones (a pesar de haberlas diferenciado al mencionarlas) corresponden al mismo momento

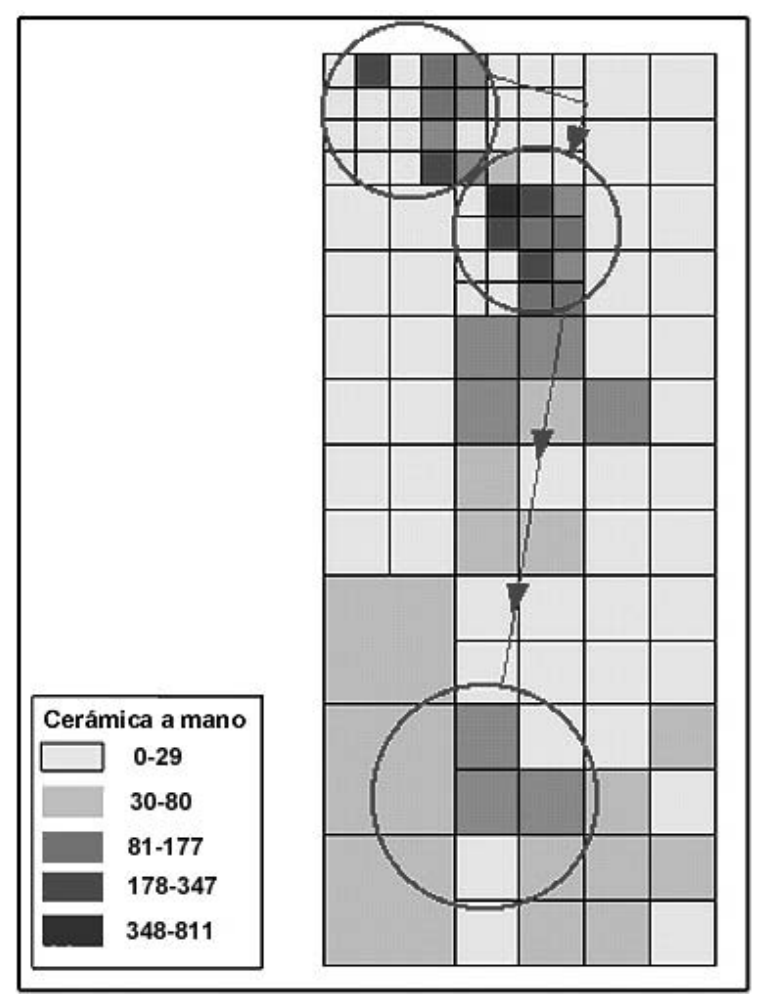

Figura 5. Representación de concentraciones de cerámica a mano en la trama de cuadrículas de prospección del Cancho Gordo (La Cabrera, Madrid) 


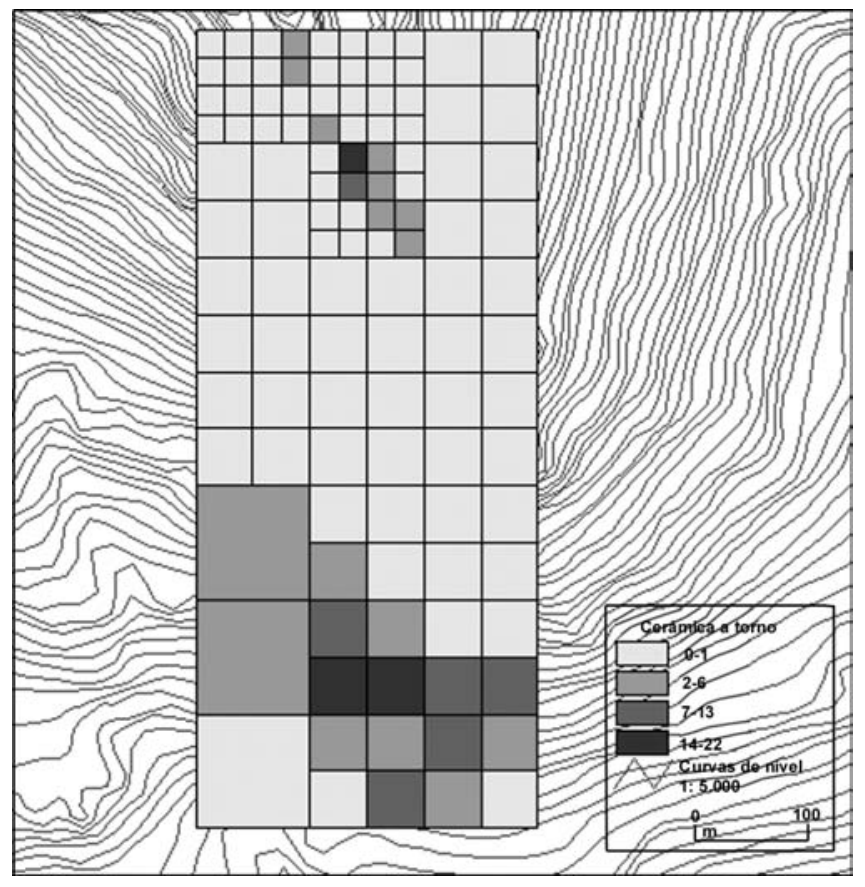

Figura 6. Distribución de cerámica a torno en el cerro del Cancho Gordo (La Cabrera, Madrid)

de ocupación ya que el material que se ha recuperado en ambos conjuntos es similar y ambas acumulaciones se encuentran a escasos metros de distancia. La tipología del material cerámico pone en relación las dos concentraciones: cerámica decorada que por su tipología puede encuadrarse en un momento claro de la Prehistoria reciente. La presencia de decoración incisa con motivos en zig-zag y líneas simples constituye uno de los máximos exponentes de la «facies Cogeces» del Bronce Medio. El predominio de cazuelas carenadas, decoradas o sin decorar completa el grupo de cerámicas del Bronce Medio, llegando incluso hasta momentos del Bronce Final a la vista de los fragmentos de cerámica aparecidos con decoración de boquique.

Por otro lado, se distinguía igualmente una concentración de material cerámico en el tercio inferior del cerro. La cota a la que se encontraba esta concentración era de 1.250 y 1.275 metros con una pendiente de $15^{\circ}$ a $20^{\circ}$, menos pronunciada que las que se documentaron a media ladera (mayores de $30^{\circ}$ ). Se interpretó esta concentración como el desplazamiento de una parte de fragmentos cerámicos de las concentraciones de la parte superior del cerro que se precipitaron por la ladera hasta llegar a zonas con menos pendiente por lo que probablemente esta acumulación no fuera debida a una ocupación del cerro a esta cota.

Con respecto a las cerámicas realizadas a torno, se deben aclarar varias cuestiones. Primeramente, parece evidente la escasez de cerámica a torno en relación a la manufacturada, como se observa en la figura 6 . Es posible que esto fuera consecuencia de una ocupación en el cerro del Cancho Gordo más prolongada de sociedades manufactureras de cerámica y que desde la introducción del torno el cerro dejara de ser habitado con tanta intensidad. No obstante, debido a que son puras conjeturas sería necesaria la realización de una excavación o sondeo para comprobar la duración de la ocupación del Cancho Gordo a lo largo del primer milenio a.C.

En la reproducción gráfica de la distribución de cerámica a torno en el cerro se pudo apreciar la acumulación de material en dos zonas: una en la parte superior del cerro y la otra en la mitad inferior del mismo. En el resto de las cuadrículas no aparecieron evidencias de esta tipología cerámica, a pesar de haber sido prospectadas con intensidad. Contando con materiales únicamente de superficie, se podían considerar dos hipótesis para explicar la distribución de las cerámicas a torno: la primera de ellas podría responder a un asentamiento en la parte superior del cerro al igual que ocurría con las cerámicas a mano. De este modo se entendería que el material cerámico de la concentración en la parte inferior del cerro fuera consecuencia del desplazamiento de los fragmentos cerámicos desde cotas superiores. La segunda hipótesis, por el contrario, apuntaba la posibilidad de un único asentamiento en la parte inferior del cerro.

Para la localización de los asentamientos durante el II y I milenio a. C. en el cerro de La Cabrera era necesaria la integración de aplica- 
ciones adicionales como la intensidad del rodamiento de los fragmentos y el análisis espacial del yacimiento.

\subsubsection{Distribución por la intensidad de rodamiento}

Para comprobar el desplazamiento de los fragmentos en superficie durante el periodo de tiempo transcurrido desde su disposición primaria hasta momentos actuales, se añadió a la tabla de atributos de las cerámicas un factor nuevo: la intensidad del rodamiento. Por intensidad del rodamiento se consideró el estado de conservación en que aparecen los fragmentos cerámicos teniendo en cuenta las alteraciones producidas por agentes naturales (clima, vientos) y mecánicos (erosión). La intensidad del rodamiento de los fragmentos era una variable que podía aclarar algunos de los procesos protagonizados por el material arqueológico, entre los que destacaba el mayor o menor desplazamiento de los fragmentos o las alteraciones químicas que hubieran podido sufrir.

La intensidad del rodamiento de un fragmento cerámico es un factor cualitativo que fue clasificado siguiendo tres categorías: muy rodado, rodado y poco rodado, dependiendo del afilado de las aristas de los fragmentos, de su alteración química y de la presencia de fracturas recientes. Con el objetivo de conseguir una muestra homogénea para la intensidad del rodamiento de los fragmentos cerámicos se realizó el cómputo por cada cuadrícula y sector de la trama general de la prospección. De este modo, y dado que el número de fragmentos por cuadrícula era muy desigual, se analizó la intensidad de rodamiento en un porcentaje equivalente en cada cuadrícula. La muestra de un $50 \%$ de los fragmentos recuperados por cuadrícula con un mínimo de una pieza, fue el porcentaje considerado suficiente para el análisis del rodamiento del conjunto cerámico del cerro del Cancho Gordo. En el gráfico I se han incluido los resultados de los análisis de la intensidad de rodamiento por cada cuadrícula. Sin embargo, con estos gráficos de porcentajes resultaba difícil establecer comparaciones con otros gráficos con variables cuantitativas (cerámica a mano y a torno). Por consiguiente, se identificaron las tres categorías del rodamiento mencionadas anteriormente como variables numéricas: muy rodado (3), rodado (2) y poco rodado (1). La comparación de los diferentes gráficos (de intensidad de rodamiento y de datos de fragmentos de cerámica a mano y a torno) permitiría establecer patrones de distribución del material cerámico. Los gráficos de intensidad del rodamiento de los fragmentos cerámicos constituyen una variable estimativa y los resultados obtenidos son puramente orientativos.

Por los gráficos, las zonas donde el grado de rodamiento era superior correspondían a la parte inferior del cerro y a media ladera. El hecho de que en la parte inferior del cerro indicara el valor de rodamiento más alto de los fragmentos cerámicos del cerro se entendió como consecuencia de la agresión de agentes naturales (erosivos) que los hayan desplazado distancias largas. Por tanto, era posible pensar que estos materiales cerámicos con evidencias claras de rodamiento se hubieran desplazado desde cotas superiores de la elevación. Se podía afirmar casi con total seguridad que la concentración de restos cerámicos que aparecía en la parte inferior del cerro se hayan desplazado por efectos de erosión y del paso del tiempo desde la parte superior del cerro.

El grado de rodamiento de las cuadrículas a media ladera ( $\mathrm{d} 6 \mathrm{y}$ e6) en cotas entre los 1.325 y 1.425 metros de altura resultaba un dato igualmente interesante. Los procesos postdeposicionales de la parte superior del cerro desplazaron los materiales a cotas inferiores a través de la pendiente, acumulándose éstos en zonas donde el desnivel se suaviza. Es justamente en esta zona donde se apreciaba un rellano en la pendiente, por lo que es un área propicia para la acumulación del material procedente de la parte superior del cerro.

Las cuadrículas con el máximo rodamiento de sus fragmentos coincidían con una de las concentraciones de mayor material arqueológico a mano (Figura 7). Si se contrastan ambos resulta-

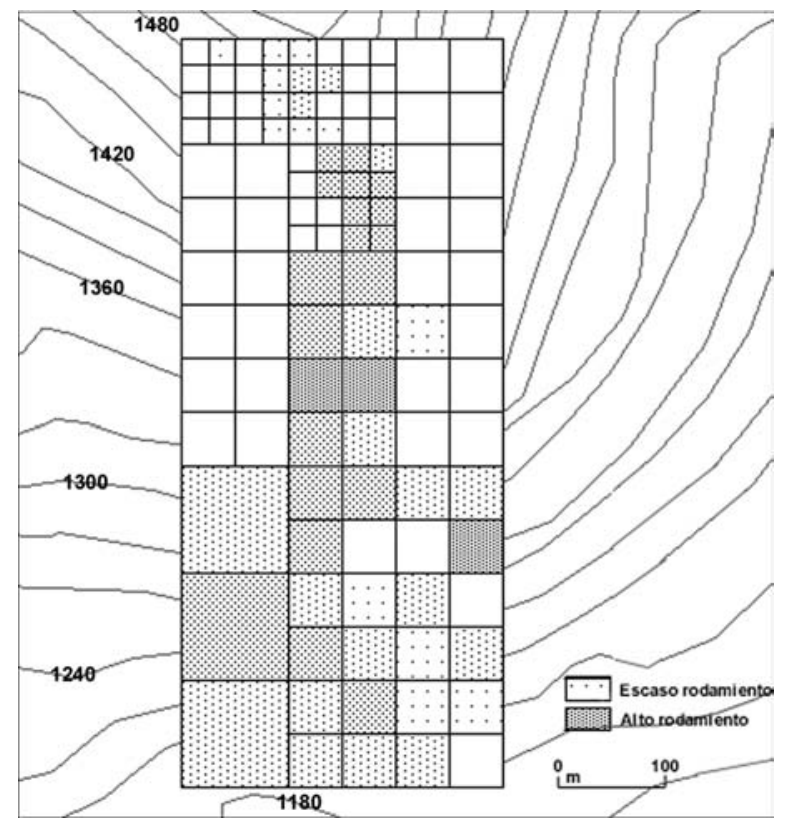

Figura 7. Representación del grado de rodamiento de los fragmentos recuperados en la prospección del cerro del Cancho Gordo (La Cabrera, Madrid) 


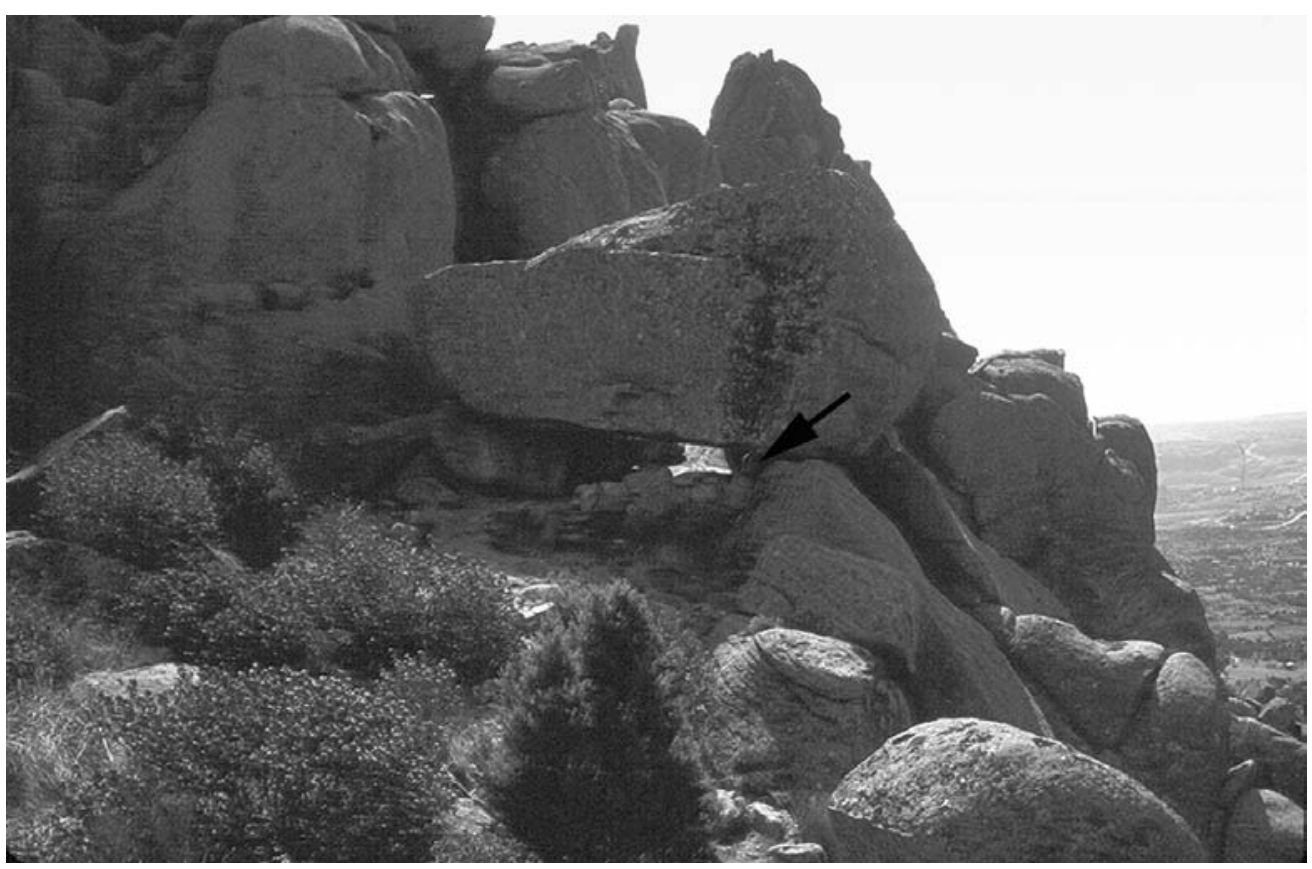

Figura 8. Vista del abrigo localizado en el cerro durante la prospección en La Cabrera

dos se puede llegar a la siguiente conclusión: la acumulación de material cerámico a mano de esta zona era debida al desplazamiento de los fragmentos como consecuencia de los grandes desniveles de la pendiente. Los fragmentos cerámicos se desplazaron desde la parte superior del cerro, por lo que presentaban una mayor intensidad en el rodamiento en relación al resto de los materiales de otras cuadrículas, y se acumularon en una zona donde el escaso desnivel no permitía su desplazamiento hacia zonas inferiores.

Por otro lado, y con toda probabilidad, la concentración de cerámica en la parte superior del cerro con evidencias de un rodamiento intenso fuera consecuencia directa de la intensa exposición de la cerámica a agentes erosivos, como fuertes cambios climáticos, precipitaciones, etc.

Con respecto a las zonas de menor intensidad de rodamiento, aparecen en el mapa de distribución de fragmentos cerámicos tres áreas diferenciadas. En la primera de las concentraciones, localizada en la parte superior del cerro, los fragmentos cerámicos recogidos durante la prospección mostraban escasas evidencias de rodamiento y su estado de conservación era óptimo. La segunda concentración de material correspondía a una zona localizada en el collado de la ladera. El sector de la cuadrícula que establecimos en

10.Uno de los factores que apoyan esta idea de ocupación de esta zona del cerro es evidente potencia estra- esta área se localizaba entre dos grandes paredes de granito sobre una superficie plana del terreno. Estas paredes de granito forman lo que podría considerarse un abrigo (Figura 8) y a juzgar por lo poco rodado que aparecía el material, se puede aventurar esta zona como uno de los lugares de ocupación del cerro durante la Prehistoria reciente ${ }^{10}$. La sospecha de que esta zona corresponda a una ocupación en abrigo responde a paralelos con otros asentamientos en los alrededores del cerro del Cancho Gordo durante el III milenio a.C., como ocurre en la Cueva del Aire, Patones (Fernández Posse, 1980) o la Cueva de los Enebralejos, Segovia (Municio y Piñón, 1990). Por último, la tercera concentración de material con escaso rodamiento se localizaba en la parte inferior del cerro.

Asegurar absolutamente que estas tres concentraciones de material cerámico con mínimas evidencias de rodamiento y alteración eran consecuencia de ocupaciones en el cerro resultaba difícil. Las zonas de mayor y menor intensidad de rodamiento parecían quedar claras pero debían ser consideradas como capa adicional de información dentro del estudio y ser contrastadas con otros datos obtenidos a partir de la prospección. En la interrelación de los datos de la intensidad de rodamiento y las distribución de las cerámicas en el cerro se observaron algunos aspectos:

tigráfica que se percibió en un área del abrigo debido a hoyos realizados posiblemente por furtivos. 
- En el estudio de intensidad del rodamiento de los fragmentos cerámicos de cotas inferiores la media de los fragmentos era elevada, excepto en un sector en particular donde el material presentaba escasas evidencias de rodamiento (A72). Este sector coincidía igualmente con una zona de considerable acumulación de fragmentos de cerámica a torno. El hecho de que se haya localizado una concentración de material cerámico a torno con escasas muestras de rodamiento en la parte inferior del cerro invitaba a suponer una ocupación en esta zona en un período de utilización del torno en la fabricación alfarera.

- La intensidad del rodamiento de las cuadrículas en la parte alta del cerro era también escasa y tras los datos de concentración de cerámica a mano en este sector del cerro, se podía pensar que los fragmentos de cerámica manufacturada de la cima, con menor intensidad de rodamiento, correspondieran a una ocupación antrópica.

\subsection{Material lítico tallado}

A pesar de ser muy escasa la representación del material lítico tallado en el cerro del Cancho Gordo, se han obtenido unos patrones de distribución que apoyan las conclusiones alcanzadas con la distribución de material cerámico. Como ocurría con el material cerámico, la industria líti- ca (en cuarcita y sílex) se concentraba en la parte superior del cerro y en menor proporción en cotas inferiores (Figura 9), al pie de la ladera.

En el estudio de la industria lítica tallada se observó un predominio de elementos de hoz tallados en sílex y la concentración de los mismos en las cotas más altas del cerro. La acumulación de los elementos de hoz en la parte superior del cerro no parecía coincidencia. Resulta difícil imaginar una actividad agrícola en cotas tan altas, principalmente por la escasez de agua para el cultivo y por las bajas temperaturas que puede llegar a alcanzar la cima del cerro, por lo que parecía lógico pensar que dichos elementos de hoz, formando parte de herramientas de hoz, fueran utilizados en la siembra en cotas menos elevadas y de mayor productividad.

En la figura 9 se identificaban varias zonas de concentración de industria lítica: una en la parte superior y otra en la inferior. Sin embargo, es posible que estas acumulaciones no fueran consecuencia de distintas ocupaciones del cerro, sino más bien al mismo asentamiento en la parte superior del cerro. Probablemente la acumulación de las cotas inferiores correspondiera a desplazamientos de los materiales desde la parte superior del cerro. Por tanto, la ocupación de la parte superior del cerro era la única posibilidad válida y las acumulaciones que se identificaban correspondían a la distribución y desplazamiento de los materiales a lo largo de los años.

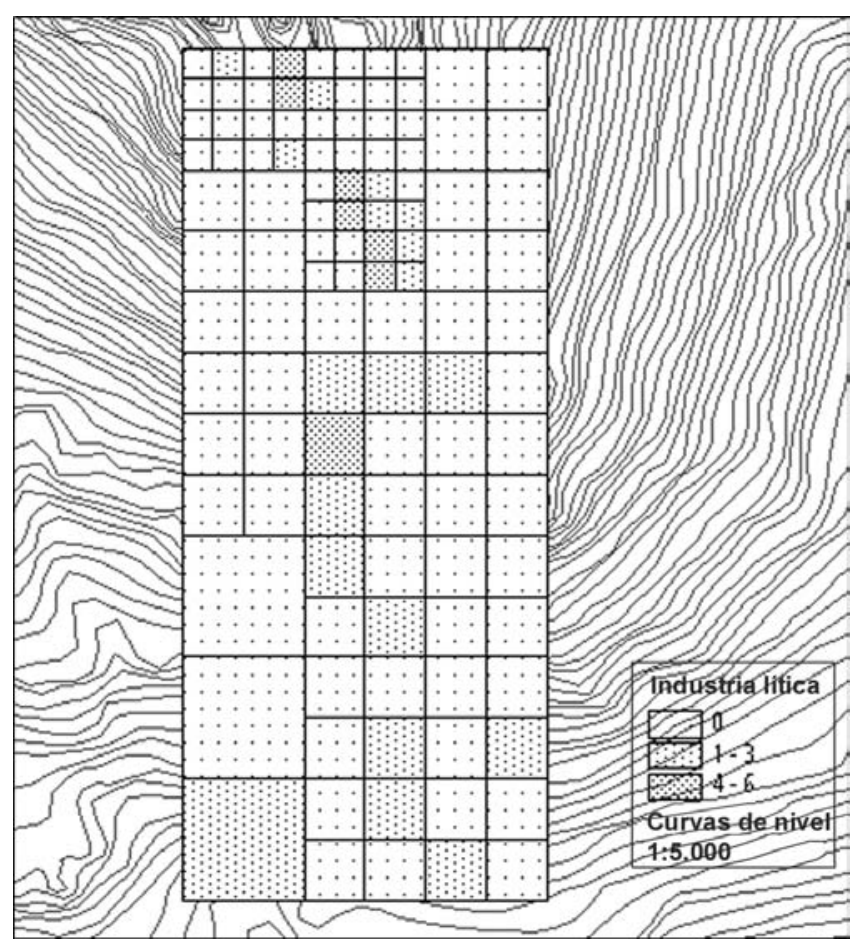

Figura 9. Distribución de la industria lítica en la trama de prospección del Cerro del Cancho Gordo (La Cabrera, Madrid) 


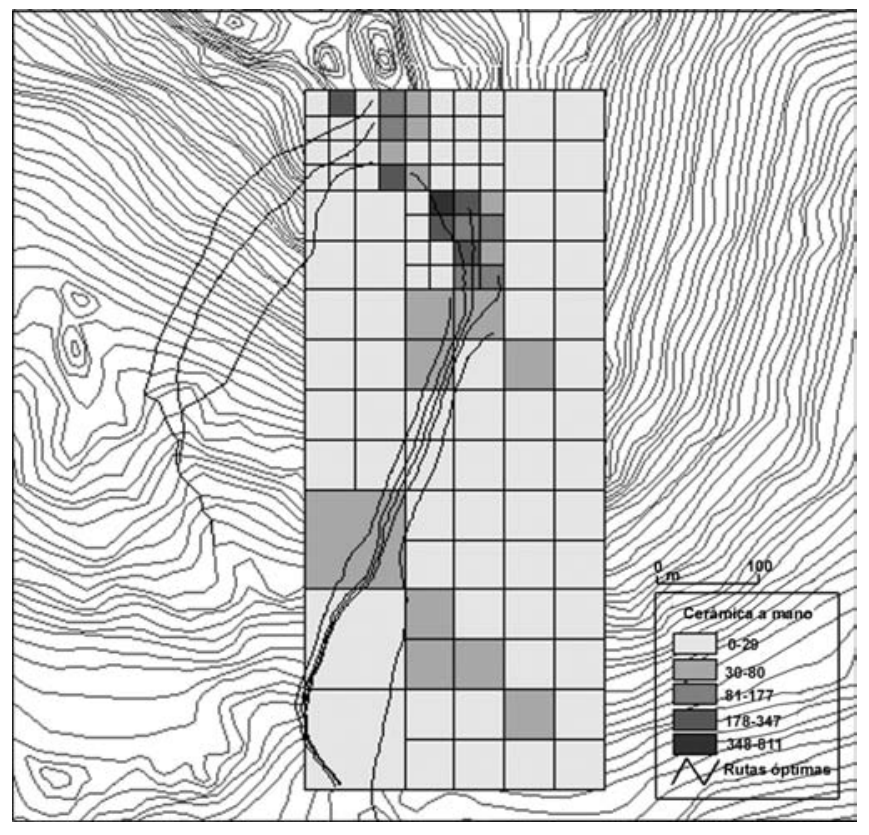

Figura 10. Representación del recorrido de rutas óptimas de un objeto desde la parte superior del cerro del Cancho Gordo (La Cabrera, Madrid)

\subsection{Una herramienta adicional del SIG para la determinación de rutas ópti- mas de desplazamiento}

Para interpretar con exactitud el mapa de distribución de la intensidad del rodamiento de los fragmentos cerámicos se contó nuevamente con la ayuda del Sistema de Información Geográfica. Para ello, se introdujo una capa de información adicional al SIG que podría aclarar las hipótesis del estudio. Esta capa adicional de información establecía las rutas óptimas de desplazamiento de objetos desde un punto marcado previamente. Para el estudio del Cancho Gordo se aplicó esta herramienta para describir la trayectoria que un fragmento cerámico recorría desde la parte superior del cerro hasta la parte inferior. De este modo, se podría contrastar la información de esta nueva cobertura con los datos de rodamiento y acumulación del material obtenidos en la prospección y así poder explicar las distribuciones del material arqueológico recuperado en el cerro del Cancho Gordo. Estableciendo el punto inicial de desplazamiento de un objeto en la parte superior del cerro en zonas de mayor concentración de material y menor grado de rodamiento, el Sistema de Información Geográfica describiría las rutas óptimas por las que un objeto desde el punto de partida marcado, rodaba hasta cotas inferiores del cerro.

En la figura 10 se observa el resultado final de las rutas óptimas que con mayor probabilidad recorre un objeto desde lo alto del cerro del
Cancho Gordo hasta la parte inferior del mismo. Entre las líneas de recorrido que aparecen en la figura destaca la coincidencia en la mayoría de los casos en una misma ruta hacia la parte inferior del cerro y la concentración de las mismas en una franja relativamente estrecha de la ladera. Si fueran éstas las rutas recorridas por los fragmentos cerámicos del cerro del Cancho Gordo, se debería tener evidencias de concentración de material en las zonas por las que supuestamente atraviesa un objeto en su descenso por la ladera. En efecto, en la distribución de los fragmentos cerámicos a mano y a torno, las concentraciones de material se localizaban en las cuadrículas por las que atraviesan las rutas de desplazamiento de los objetos desde la parte superior del cerro.

En el mapa de distribución de cerámicas a mano se observaba la coincidencia de las acumulaciones de material a media ladera con el recorrido de las rutas óptimas de desplazamiento. Esta concurrencia de datos demuestra una vez más que la acumulación de material a media ladera era originada al desplazamiento de los materiales desde las cotas más elevadas del cerro. Por otro lado, en el tercio inferior del cerro ocurre algo diferente a lo que explicábamos para la cima. Las rutas óptimas que describía el SIG en este sector del cerro no coincidían con la concentración de cerámica a torno. Parece claro pensar que la acumulación de material cerámico a torno de la parte inferior de la ladera pudiera deberse a un asentamiento durante la segunda mitad del I milenio a. C. en esta zona baja de la elevación. 


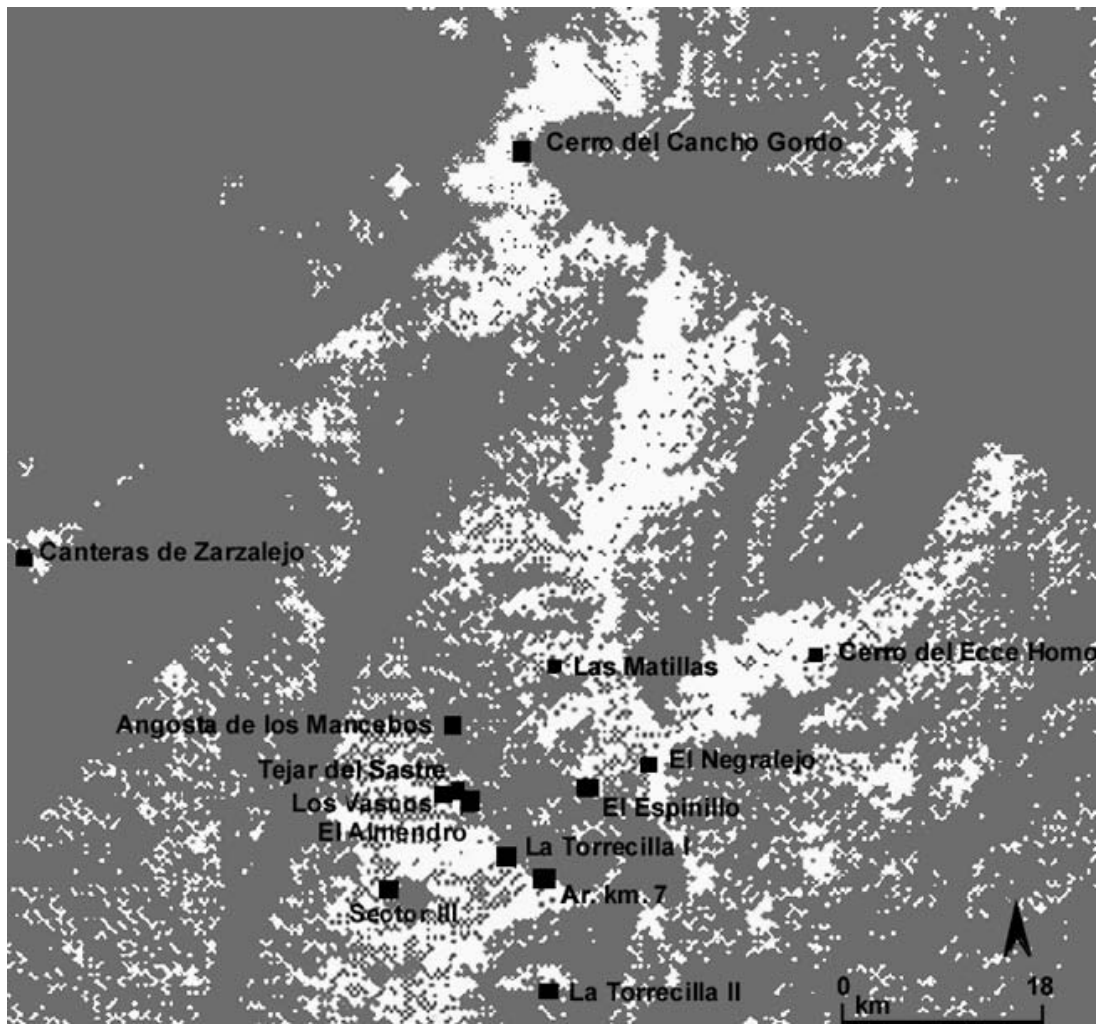

Figura 11. Mapa de visbilidad desde el cerro del Cancho Gordo hacia el sur de la vega madrileña (blanco= visible, gris= no visible)

\section{Analisis espacial del yacimiento}

\subsection{El cerro del Cancho Gordo y los grupos vecinos de la vega madrileña: visibili- dad e intercambio de materias primas}

La visibilidad de un yacimiento es uno de los factores importantes a tener en cuenta en el estudio del mismo. Evidentemente, el factor de visibilidad de un yacimiento cobrará mayor o menor importancia dependiendo de la vocación del grupo que lo ocupe. De este modo, según se trate de un grupo de vocación puramente agrícola, o ganadero o de si el terreno de cultivo es mayor o menor, la visibilidad tendrá una mayor significación. Habitualmente se entiende que los asentamientos en altura tienen como uno de sus objetivos el control visual del territorio ${ }^{11}$. La dificultad radica, por tanto, en establecer las razones que llevaron a el grupo o grupos de La Cabrera a una ocupación en cotas tan elevadas. En la meseta norte durante el Bronce medio y final aparecen, al igual que en el ámbito madrileño, asentamientos en altura sobre emplazamientos destacados junto a otros ubicados en el

11.Durante la I Edad del Hierro en el ámbito madrileño, los asentamientos pasan a ocupar zonas de mayor altura a lo largo de cursos secundarios para dominar fondo de los valles. La relación entre estos dos tipos de asentamientos es difícil de precisar pero en ocasiones se ha supuesto que hubiera una preeminencia de los primeros, amurallados en la mayoría de los casos, sobre los segundos, dispuestos para la agricultura (Bellido, 1996, 95). No parece claro que esta "jerarquía" se pueda establecer para la región septentrional madrileña, a pesar de existir una estrecha relación entre las culturas de la Edad del Bronce de la meseta sur y la norte. Igualmente, la inexistencia de murallas u otro tipo de construcción de defensa en los yacimientos localizados en altura de la meseta sur (las Canteras de Zarzalejo, el cerro del Ecce Homo o la Muela de Alarilla sirven como ejemplo) apoyan esta idea. Evidentemente, los yacimientos mencionados se localizan en zonas de dominio de vega y de control de territorio pero creemos muy arriesgado establecer una jerarquía social entre los asentamientos en altura y los de la vega basada únicamente en un factor espacial (Díaz del Río, 1998).

El yacimiento del cerro del Cancho Gordo está localizado en altura. Desde los aproximadamente 1.500 metros de altura de la cima se obtie-

un mayor territorio y controlar los pasos y caminos estratégicos (Blasco y Baena, 1999, 201). 
ne una visibilidad muy amplia, llegando incluso a alcanzar los $50 \mathrm{Km}$ de distancia (Figura 11). Parece claro pensar que la visibilidad del cerro juega un papel importante en su relación con los asentamientos de la Edad del Bronce en el ámbito madrileño. Para establecer la intervisibilidad entre el cerro del Cancho Gordo y los distintos yacimientos localizados en la vega y serranía madrileña, se decidió elaborar un mapa de visibilidad en el que se definiera la franja de visión del cerro de nuestro estudio. De esta manera se podría de valorar la importancia de la ocupación del cerro en su parte más elevada. De esta manera, se observa en la figura 11 que la mayoría de los yacimientos son visibles desde el cerro, tanto los asentados en llano (Tejar del Sastre, El Espinillo) como los que ocupan cerros altos (Ecce Homo, Canteras de Zarzalejo). Para comprobar si esta visibilidad desde cerro era recíproca desde el resto de yacimientos, decidimos crear mapas de visibilidad desde ciertos asentamientos. De tesa manera se observó que el Cancho Gordo estaba dentro del campo visual del cerro del Ecce Homo y de El Negralejo. Desde estos dos yacimientos del Bron-ce Final de la región madrileña la visibilidad del cerro de La Cabrera parece claro, lo que parecía confirmar que la localización del cerro del Can-cho Gordo estaba sujeta a un factor de destacada importancia: la visibilidad. Se ha comentado en ocasiones que "la referencia visual de la sierra debió de ser habitual en muchos de los asentamientos en bajo" (Blasco y Baena, 1999, 202) y que esta intervisibilidad queda justificada en los múltiples contactos que mantuvieron los asentamientos de la vega con la zona serrana de la región de Madrid. Estos contactos se mantenían principalmente para el abastecimiento de materias primas de yacimientos de la vega en los que se carecía de ciertas rocas y minerales que aparecen precisamente en la zona serrana de la provincia. De esta manera, puede pensarse en el cerro del Cancho Gordo como el yacimiento de referencia para los asentamientos de la vega en su "búsqueda" de materias primas durante la Edad del Bronce.

\section{¿Intercambio de materias primas?}

La localización del cerro del Cancho Gordo, en la serranía madrileña, con una altura elevada y próxima a determinadas fuentes de aprovisionamiento de materias primas (granito, fibrolita, cobre) podría hacer de este asentamiento un punto importante de contacto entre los grupos de la serranía y los de la vega durante el III y II milenio a.C. Es probable que el cerro del Cancho Gordo sirviera como de punto de referencia para el abastecimiento de materias primas de los grupos asentados en las cuencas fluviales, lejos de las fuentes de aprovisionamiento. La necesidad de abastecimiento de granito, o fibrolita de determinados grupos asentados en las cuencas fluviales pudo estimular el intercambio de ciertas materias primas con la gente del cerro del Cancho Gordo en donde aparecen materias primas cuyo aprovisionamiento se encuentra fuera del entorno inmediato. Por un lado, las poblaciones del llano se abastecerían de granito, fibrolita y de minerales (cobre, estaño) y por otro lado, el grupo del cerro de La Cabrera se abastecería de sílex ya que los afloramientos de esta materia se localizan en la zona de la vega, cerca de las terrazas cuaternarias.

En efecto, el aprovisionamiento de granito y fibrolita únicamente se da en la sierra norte de Madrid, próximo al cerro del Cancho Gordo o en zonas más alejadas como Sierra Morena localizada a cientos de kilómetros. Si se considera la distribución de molinos de granito y de hachas de fibrolita en la región madrileña se observa que en la mayoría de los casos los asentamientos se encuentran a más de $40 \mathrm{Km}$. de distancia de las fuentes de abastecimiento de la sierra norte. La dispersión de estos útiles indica que hubo un desplazamiento de estas gentes en la búsqueda de estas materias primas, lo que supondría el empleo de más de una jornada hasta alcanzar estos lugares. Tanto si el desplazamiento se realizó para el abastecimiento de materias primas como si fue para un intercambio de objetos entre grupos vecinos, no cabe la menor duda de que el contacto entre estos grupos existió.

Posiblemente estos contactos se realizasen a través de la red hidrográfica de la región. En el caso de las gentes del cerro del Cancho Gordo es muy probable que fuera la cuenca del Jarama el medio de transporte y de contacto para la realización de sus transacciones con los grupos de la llanura. Probablemente las gentes del cerro del Cancho Gordo se desplazaron a la cuenca fluvial del Jarama en algún momento, ya que existen evidencias claras de materiales procedentes de dicha cuenca (cuarcita, sillimanita) en el yacimiento.

\subsection{El cerro del Cancho Gordo: zona de contacto entre las dos mesetas}

Por último, es necesario hacer alusión a la localización del cerro del Cancho Gordo con respecto de las mesetas norte y sur. Como se ha mencionado anteriormente, es muy probable que el cerro del Cancho Gordo mantuviese una estrecha relación de contacto con los grupos vecinos de la vega madrileña. La proximidad del 


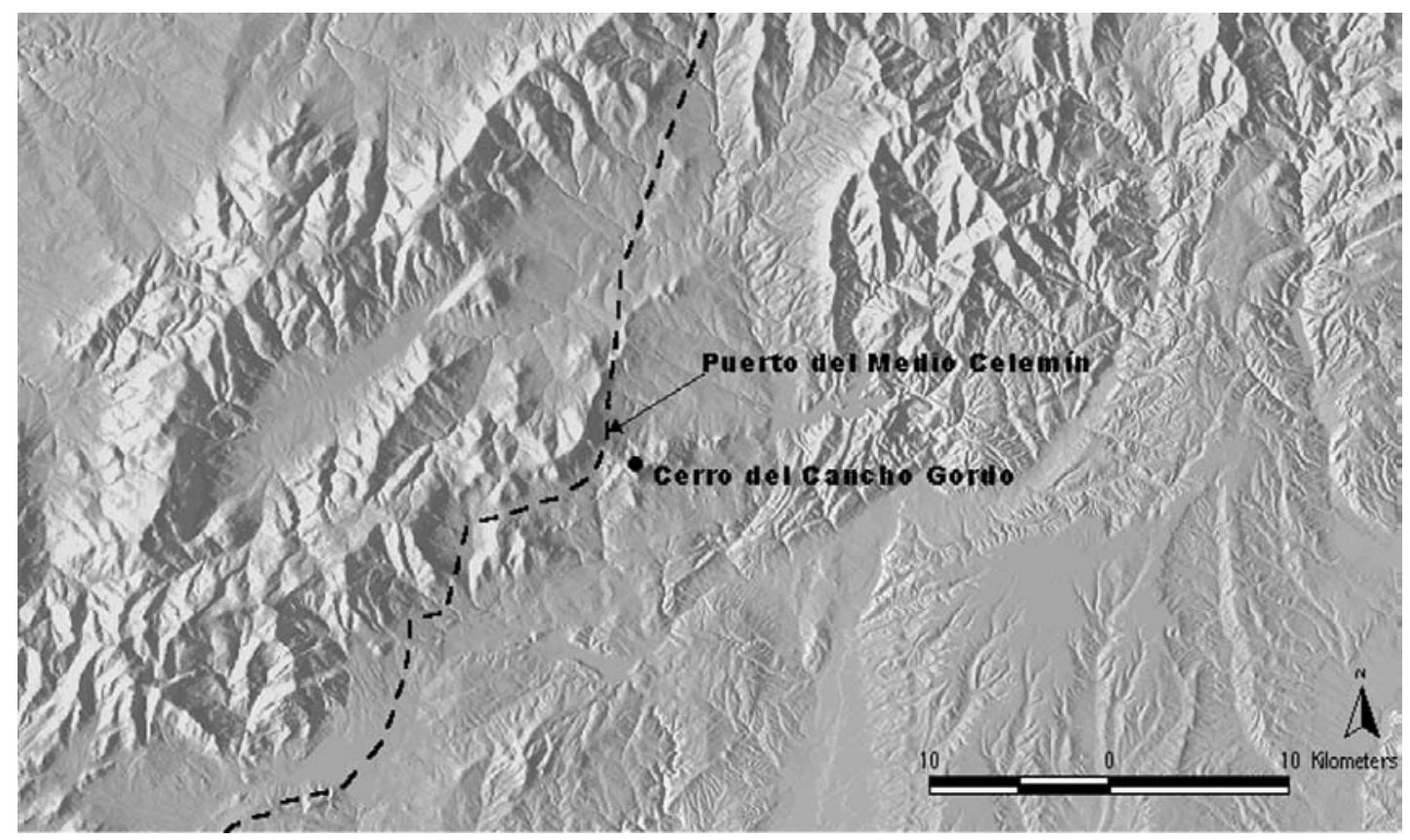

Figura 12. Trazado de la cañada Real Segoviana a su paso por la Sierra de La Cabrera, Madrid

yacimiento de La cabrera a las fuentes de aprovisionamiento pudo facilitar este contacto entre grupos durante el III y II milenio a. C.. Asimismo, el cerro de la Cabrera se encuentra dominando gran parte de del área septentrional de la región madrileña. La visibilidad que se obtiene desde el cerro del Cancho Gordo hacia el norte alcanza un extenso área (unos $900 \mathrm{~km}^{2}$ ) en el que se incluyen los cursos fluviales actuales y los pasos de comunicación entre las dos mesetas (Puerto de Somosierra).

Se debe recordar los caminos recorridos por los ganaderos trashumantes a lo largo de la historia. Estas rutas de trashumancia o vías pecuarias se han venido utilizando desde antiguo para el traslado del ganados desde los pastos de verano en las montañas de norte y centro de la península (agostaderos o pastos estivales) a los de invierno (invernaderos o "extremos") en las dehesa extremeñas, andaluzas y manchegas, y viceversa. En su conjunto forman un complejo sistema de caminos de distinta anchura, hasta un máximo de 70 metros en las cañadas reales. A lo largo del recorrido de las cañadas aparecían abrevaderos donde bebía el ganado, descansaderos y majadas ${ }^{12}$. Por la provincia de Madrid pasan tres de las cañadas reales más importantes: la cañada real riojana, la soriana oriental y la segoviana. Es esta última la que interesa en este estu-

12.Las majadas eran los lugares donde se pasaba la noche, el ganado recogido y los pastores en cobijo. dio: la cañada segoviana entra en Madrid por el Puerto de Somosierra, recorre el Valle del Lozoya, pasando por Buitrago de Lozoya y continúa hacia el sur por Bustarviejo, Miraflores, Manzanares el Real hasta El Escorial. A su paso por Buitrago, la cañada atraviesa el Puerto del Medio Celemín, a tres kilómetros del cerro del Cancho Gordo. Desde el cerro del Cancho Gordo se distingue gran parte del recorrido de la ruta de trashumancia a su paso por tierras madrileñas (Figura 12).

En torno a la utilización de estas vías o rutas y por tanto, al origen de la trashumancia hay numerosas teorías. En un repaso bibliográfico encontramos opiniones contrastadas a lo largo de este último siglo (Sánchez Moreno, 1998). Así, a principios del siglo XX se aceptaba la trashumancia en la Iberia prerromana como antecedente a la organización mesteña (Klein, 1979) ${ }^{13}$, mientras que a partir de los años 50 se niega la existencia de la trashumancia como tal con anterioridad a su oficialidad medieval. En las últimas décadas de nuestro siglo, la práctica trashumante durante la Prehistoria Reciente volverá a ser tomada en consideración ya que incluso se llego a relacionarla durante el III milenio a. C. Estas ideas apoyaban la existencia de una trashumancia para el período Calcolítico de acuerdo a ciertos elementos simbólicos que se relacionaban

13.Citado en Sánchez Moreno, 1998. 

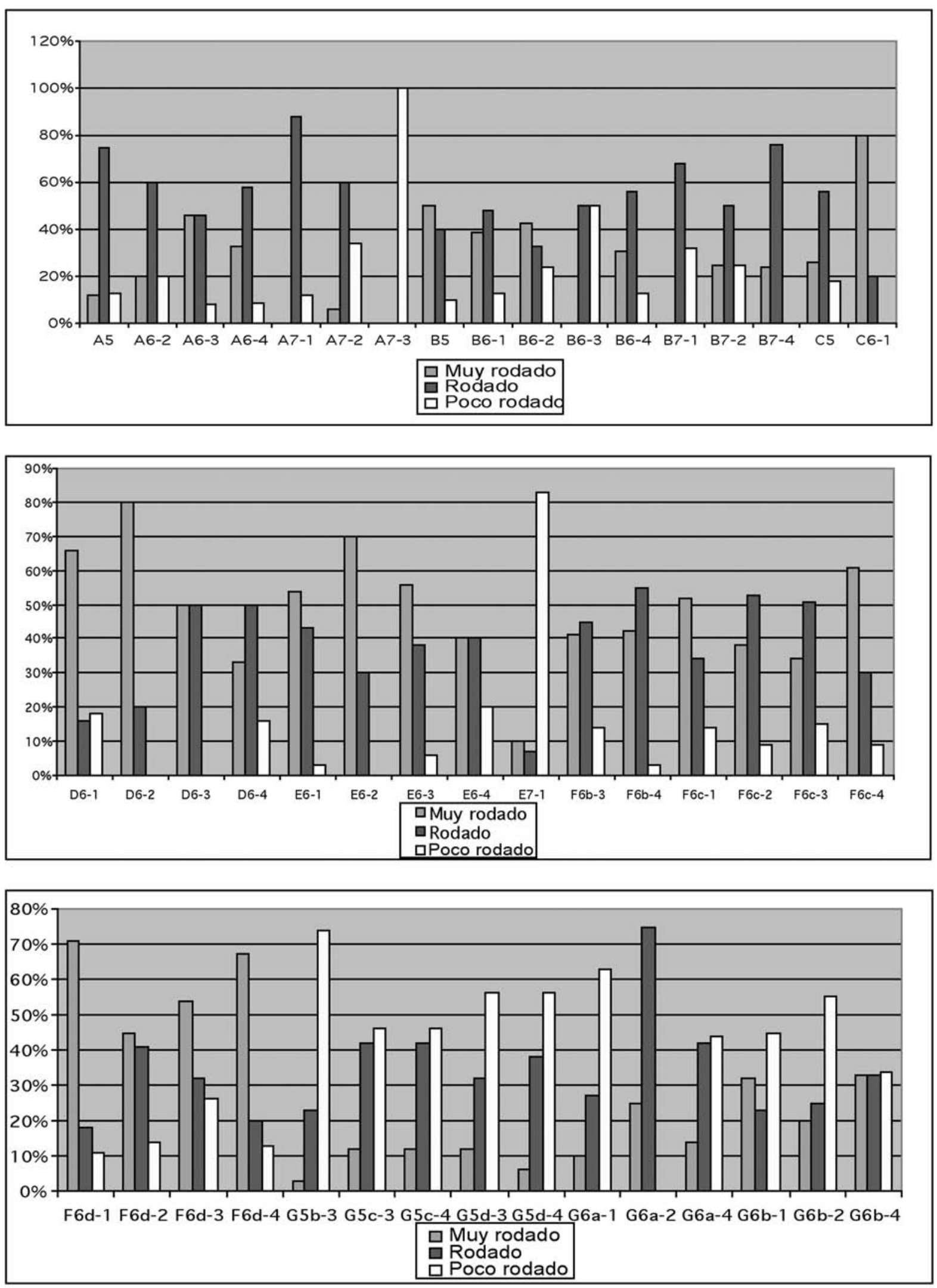

Gráfico I. Análisis de la intensidad de rodamiento del material cerámico por cuadrículas de prospección del cerro del Cancho Gordo. 
con dicha práctica: los megalitos como marcas territoriales (Higgs, 1976). Sin embargo, esta teoría sería refutada alegando la ausencia de estructura técnica de esas sociedades para garantizar el paso de pastores y ganados por tierras lejanas (citado en Sánchez Moreno, 1998). Igualmente, se ha querido relacionar la práctica de la trashumancia a grupos del Bronce Final, en concreto durante el Horizonte de Cogotas I. Uno de los principales argumentos utilizados era la amplia dispersión de sus cerámicas (excisas y de boquique) por el ámbito peninsular localizadas en el extremo de vías o cañadas ${ }^{14}$. Sin embargo, a principios de la década de los 90, la idea de los "móviles pastores de Cogotas" (Fernández-Posse, 1998, 116) fue perdiendo credibilidad sustentada en la interpretación de la fosas de los campos de hoyos como almacenes de grano agrícola que contuvieran un excedente de grano, lo que implicaría una economía predominantemente agrícola. Del mismo modo, los estudios de analítica de pastas de la cerámicas (Blasco, Arribas y Martín de la Cruz, 1994) "están revelando el carácter local de las producciones de tipo Cogotas I en la orla periférica" (Sánchez Moreno, 1998) lo que descartaría la dispersión del material cerámico por el territorio peninsular en relación con la movilidad ganadera.

A pesar de que la pretensión de llevar las prácticas de trashumancia hasta momentos tan antiguos como la Prehistoria reciente del III milenio a.C. sigue siendo un tema discutido , parece no haber dudas de que "la ganadería móvil tuvo un peso decisivo en la economía de los pueblos prerromanos al menos desde el final de la I Edad del Hierro" (Vega, Cerdeño y Córdoba de Oya, Internet). Por tanto, es posible pensar que las cañadas reales se trazasen sobre estas vías anteriores. Con esto, se pretende apuntar la posibilidad de que el cerro del Cancho Gordo, al encontrarse tan próximo a la cañada real segoviana fuera un punto importante en el control de vías, bien se aprovechara para intercambio de objetos o de paso de trashumancia. En este sentido, el contacto entre las dos mesetas sería posible a partir de las vías de comunicación y de "lugares estratégicos" como el cerro del Cancho Gordo.

\section{Conclusiones}

Según se ha podido comprobar a partir del estudio realizado en el cerro del Cancho Gordo, la aplicación de un Sistema de Información Geográfica ha supuesto una ayuda fundamental para el desarrollo de la investigación. La creación, por un lado, de la trama en formato digital de las cuadrículas que establecimos en el campo (cerro del Cancho Gordo) ha facilitado la percepción de la distribución espacial de los materiales arqueológicos aparecidos durante la prospección. De esta manera se pudo precisar el lugar concreto de las áreas de acumulación con respecto a la topografía del terreno. Asimismo, la creación de un Modelo Digital del Terreno del cerro del Cancho Gordo ha determinado el empleo de unas herramientas concretas de gran interés para nuestro estudio: las rutas óptimas de desplazamiento y la visibilidad del cerro.

Con respecto a las rutas óptimas de desplazamiento de objetos trazadas por el Sistema de Información Geográfica, éstas han ratificado las hipótesis de partida del estudio: el desplazamiento de material cerámico desde la parte superior del cerro hacia cotas inferiores, y la posibilidad de una asentamiento tardío en la parte inferior del cerro. Igualmente, las rutas óptimas de desplazamiento han servido para "predecir" las zonas más propensas a la concentración de material arqueológico y por lo tanto han favorecido la prospección del cerro.

El SIG ha confirmado igualmente su utilidad en el estudio espacial del cerro. Se ha podido determinar las zonas de mayor visibilidad desde el cerro comprobando de esta manera la extensa visibilidad alcanzada por un grupo asentado en el yacimiento del Cancho Gordo, constituyendo éste un lugar "estratégico" en la obtención de materias primas y probablemente como punto de referencia para los grupos asentados en la vega madrileña.

Por tanto, parece clara una vez más la utilidad de aplicación de un Sistema de Información de Geográfica en arqueología y en este caso concreto en su aplicación en una prospección.

\section{Bibliografía}

Abarquero Moras, F. J. (1997): "El significado de la cerámica decorada de Cogotas I" Boletín de Estudios de Arte y Arqueología LXIII, Valladolid, (71-96).

Agencia de medio ambiente (1982): Guía de la Cabrera, Madrid.

14.De esta manera quedaba justificada la presencia de cerámica de Cogotas I en el yacimiento granadino de Purullena (Molina y Arteaga, 1976). 
Allen, K.; Green, S.; Zubrow, E. (eds.) (1990): Interpreting Space: GIS and Archaeology, Londres.

Almagro-Gorbea M.; Benito-López, J. E., (1994): "Prospección arqueológica de Perales de Tajuña (Madrid)" Estudios de Prehistoria y Arqueología madrileñas 9, Madrid (99-109)

Almagro Gorbea, M.; Fernández-Galliano, D. (1980): Excavaciones en el Cerro del Ecce Homo (Alcalá de Henares. Madrid). Diputación Provincial de Madrid.

Amado Reillo, X. (1997): "La aplicación del gps a la arqueología" Trabajos de Prehistoria $54 \mathrm{n}^{\circ}$ 1, Madrid (155-165).

Arroyo-Bishop, D. (1991): "El sistema Archéo DATA. Hacia la creación de un S.I.A.” Complutum 1, Madrid (167-174).

Baena, J.; Blasco, C.; Quesada, F. (eds.) (1999): Los S.I.G. y el análisis espacial en arqueología, UAM.

Bellido Blanco, A. (1996): Los campos de hoyos. Inicio de la economía agrícola en la submeseta norte, Studia Archaeologica 85, Universidad de Valladolid.

Blasco, Ma C.; Baena, J. (1993): "Tratamiento de la información gráfica espacial” en A. Jimeno, J.M. Val Recio y J.J. Fernández Moreno (eds) Inventarios y cartas arqueológicas. Homenaje a Blas de Taracena, Soria, 1991, Junta de Castilla y León, Valladolid (179-189).

Blasco, Ma C.; BAENA, J. (1999): "Cambios en los patrones de asentamiento y visibilidad. El Bronce Final y la Primera Edad del Hierro en el Bajo Manzanares" en Baena, Blasco y Quesada (eds) Los S.I.G. y el análisis espacial en arqueología, UAM (195-211).

Blasco, Ma C.; Arribas, J.G.; Martín de la Cruz, J.C., (1994): "Mineralogical and textural análisis of Late Bronze Age Sherds" European Ceramic Society. Third Conference (Madrid, Septiembre, 1993), Madrid (520525).

Bullón Mata, T. (1995): "Hill Slope Erosion, Environmental Changes and Land Management on a Spanish Mountain" Physics, Chemistry and Earth, vol. 20, no 3-4, Gran Bretaña (339-344).

BuriLlo, F. (1996): "Prospección arqueológica y Geoarqueología” Arqueología Espacial 15, Teruel (67-81).

Carrobles, J.; Muñoz, K.; Rodríguez, S. (1994): "Poblamiento durante la Edad del Bronce en la Cuenca Media del río Tajo" La Edad del Bronce en Castilla-La Mancha, Actas del Simposio; 1990, Toledo (173-200).

DíAz DEL Río, P. (1998): El III y II milenios A.C. en el entorno de la campiña madrileña, Tesis Doctoral Inédita, Universidad Autónoma de Madrid.

EsPiAgo, J.; BAENA J. (1999): "Los Sistemas de Información Geográfica como tecnología informática apli- cada a la arqueología y a la gestión del patrimonio" en J. Baena, C. Blasco y F. Quesada (eds.) Los S.I.G. y el análisis espacial en Arqueología, UAM, (7-66).

FERnÁNDEZ-Posse, M ${ }^{\mathrm{a}}$ D. (1980): "Los materiales de la Cueva de Patones (Madrid)" Noticiario Arqueológico Hispánico 10, Madrid (39-64).

FERnÁNDEZ- Posse, Ma D. (1998): La investigación protohistórica en la Meseta y Galicia, Editorial Síntesis, Madrid

FOARD, G. (1978): "Systematic fieldwalking and the investigation of Saxon settlement in Northamptonshire" World Archaeology, vol. 9, no 3 (357-374).

GonZÁlez, C. A. (1998): "GIS, Arqueología y Paisaje: una crítica constructiva” Arqueología Espacial 19-20, Teruel (71-77).

HARRIS, T.; LOCK, G. (1995): "Toward an evaluation of GIS in European Archaeology" en G. Lock y Z. Stancic (eds.) Archaeology and Geographical Information Systems, Londres (349-366).

Higgs, E. S. (1976): "The history of European agriculture: the uplands" Philosophical Transactions of the Royal Society of London, Series B, 275 (159-173).

Kvamme, K. L. (1995): "A view from across the water" en G. Lock y Z. Stancic (eds.) Archaeology and Geographical Information Systems: a european perspective, Londres (1-14).

Lock, G.; STAncic, Z. (1995) (eds.): Archaeology and Geographical Information Systems: a european perspective, Londres.

Logemann, E.; Kalkbrenner, G.; KRÜtZFeldt, B.; SchÜle, W. (1995): "Contenido de mercurio en huesos de animales domésticos y trashumancia" $1^{\circ}$ Congresso de Arqueologia Peninsular (Porto, 12-18 Octubre, 1993) Trabalhos de Antropologia e etnologia, vol XXXV, Porto.

Martínez NaVArrete, Mª I. (1988): La Edad del Bronce en la Submeseta suroriental: una revisión crítica, Colección Tesis Doctorales, ${ }^{\circ}$ 191/88, Universidad Complutense de Madrid.

Molina, F.; Arteaga, O. (1976): "Problemática y diferenciación en grupos de la cerámica con decoración excisa en la Península Ibérica" Cuadernos de Prehistoria de la Universidad de Granada I, Granada (175-214).

Municio González, L.; Piñón Varela, F. (1990): "Cueva de los Enebralejos (Pradeña, Segovia" Numantia III, Soria (51-76).

Planas Garrido, M. (2000): El yacimiento del Cancho Gordo (La Cabrera, Madrid): Aplicación de un Sistema de Información Geográfica. Memoria de Licenciatura. Universidad Autónoma de Madrid. Inédito.

Rubio, I. (2000): "Las primeras sociedades agrícolas en Madrid. Neolítico y Calcolítico Precampaniforme" 
en La arqueología madrileña en el final del siglo XX: desde la prehistoria hasta el año 2000, BAEAA 39-40, Madrid (105- 126).

Ruiz Zapatero, G.; Fernández Martínez, V.M. (1993): "Prospección de superficie, técnicas de muestreo y recogida de información" en A. Jimeno, J. M. del Val Recio y J. J. Fernández (eds) Inventarios y cartas arqueológicas. Homenaje a Blas de Taracena, (Soria, 2023 Noviembre 1991) Valladolid (87-98).

SÁnchez Moreno, E. (1998): "De ganados, movimientos y contactos. Revisando la cuestión trashumante en la Protohistoria hispana: la meseta occidental" Studia Historica. Historia Antigua, vol. 16, Salamanca (53-84).

SAVAGE, S. H. (1990): "GIS in archaeological research" en K. Allen, S.W. Green y E. Zubrow (eds) Interpreting space: GIS and archaeology, Londres, (22-32).

Stefanovic, P. (1988): "Digital elevation models", ITC Lectures Notes.

Vega, L. G.; Cerdeño, Ma L.; CóRdoba de Oya, B.: "El origen de los mastines ibéricos. La trashumancia entre los pueblos prerromanos de la meseta" (http://wwre.molina-aragon.com/historia/celtiberia/mastines.html)

Warren, R. E.; Asch, D. L. (2000): “A Predictive Model of Archaeological Site Location in the Eastern
Prairie Peninsula" en Westcott y Brandon (ed) Practical Applications of GIS for Archaeologists. A Predictive Modelling Toolkit, Taylor \& Francis, Londres (5-32).

Zubrow, E. B. W. (1990): "The fantasies of IGS software" en K.Allen, S.Green y E.Zubrow (eds) Interpreting Space: GIS and Archaeology, Londres (184-193).

\section{Cartografía utilizada}

CONSEJERÍA DE POLÍTICA TERRITORIAL (1990): Mapa topográfico de la Comunidad de Madrid, E. 1:5.000, 484 (66), Lozoyuela, Comunidad de Madrid.

CONSEJERÍA DE POLÍTICA TERRITORIAL (1990): Mapa topográfico de la Comunidad de Madrid, E. 1:5.000, 484 (67), La Cabrera, Comunidad de Madrid.

InSTITUTO GEOGRÁFICO NACIONAL (1987): Mapa Topográfico Nacional de España, E. 1:50.000, Hoja 484 (19-19) Buitrago de Lozoya, Madrid, $6^{\text {a }}$ edición.

INSTITUTO TECNOLÓGICO GEOMINERO DE ESPAÑA (1988): Mapa Geológico de España, E. 1:50.000, Hoja 484 (19-19), Buitrago de Lozoya (Mapa y Memoria explicativa), Madrid.

SERVICIO GEOGRÁFICO DEL EJÉRCITO (1997): Mapa Militar Digital de España, series $5 L$ (1:250.000) y $8 C$ (1:800.000) (zona norte), Madrid. 